\title{
Speciation and fate of trace metals in estuarine sediments under reduced and oxidized conditions, Seaplane Lagoon, Alameda Naval Air Station (USA)
}

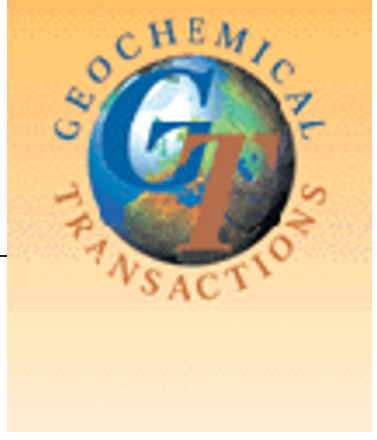

Paper

Received 27th May 2002, Accepted 16th October 2002

First published as an Advance Article on the web 20th November 2002

We have identified important chemical reactions that control the fate of metal-contaminated estuarine sediments if they are left undisturbed (in situ) or if they are dredged. We combined information on the molecular bonding of metals in solids from X-ray absorption spectroscopy (XAS) with thermodynamic and kinetic driving forces obtained from dissolved metal concentrations to deduce the dominant reactions under reduced and oxidized conditions. We evaluated the in situ geochemistry of metals (cadmium, chromium, iron, lead, manganese and zinc) as a function of sediment depth (to $100 \mathrm{~cm}$ ) from a 60 year record of contamination at the Alameda Naval Air Station, California. Results from XAS and thermodynamic modeling of porewaters show that cadmium and most of the zinc form stable sulfide phases, and that lead and chromium are associated with stable carbonate, phosphate, phyllosilicate, or oxide minerals. Therefore, there is minimal risk associated with the release of these trace metals from the deeper sediments contaminated prior to the Clean Water Act (1975) as long as reducing conditions are maintained. Increased concentrations of dissolved metals with depth were indicative of the formation of metal $\mathrm{HS}^{-}$complexes. The sediments also contain zinc, chromium, and manganese associated with detrital iron-rich phyllosilicates and/or oxides. These phases are recalcitrant at near-neutral $\mathrm{pH}$ and do not undergo reductive dissolution within the 60 year depositional history of sediments at this site.

The fate of these metals during dredging was evaluated by comparing in situ geochemistry with that of sediments oxidized by seawater in laboratory experiments. Cadmium and zinc pose the greatest hazard from dredging because their sulfides were highly reactive in seawater. However, their dissolved concentrations under oxic conditions were limited eventually by sorption to or co-precipitation with an iron (oxy)hydroxide. About $50 \%$ of the reacted $\mathrm{CdS}$ and $80 \%$ of the reacted $\mathrm{ZnS}$ were bonded to an oxide-substrate at the end of the 90-day oxidation experiment. Lead and chromium pose a minimal hazard from dredging because they are bonded to relatively insoluble carbonate, phosphate, phyllosilicate, or oxide minerals that are stable in seawater. These results point out the specific chemical behavior of individual metals in estuarine sediments, and the need for direct confirmation of metal speciation in order to constrain predictive models that realistically assess the fate of metals in urban harbors and coastal sediments.

\section{Introduction}

A recent evaluation of sediment contamination of surface waters in the United States by the US Environmental Protection Agency identified 96 watersheds, mostly urban harbors, containing metal and/or organic chemical contents that are potentially hazardous to aquatic biota. ${ }^{1}$ These harbors and coastal sediments are contaminated from past and present industrial and military waste disposal practices. One such example is the estuary sediments of the East Outfall Site of the Seaplane Lagoon, at the former Naval Air Station (NAS) Alameda located on an island in San Francisco Bay, USA (Fig. 1). The most abundant metals in the sediments are cadmium, lead, chromium, zinc, copper, and nickel. Concentrations of these metal contaminants above background levels in San Francisco Bay result from a 57 year history of military and industrial activity at this site. From 1940 to 1975, the Seaplane Lagoon received about 300 million gallons of wastewater from industrial and storm sewers from NAS Alameda. The Seaplane Lagoon and its surrounding area have been designated as a mixed-use commercial marina site in the City of Alameda land use plan. ${ }^{2}$ A concern for this site and other urban estuarine environments is the contamination of the overlying water column as metals dissolve when reduced sediments react with oxygen-rich water during bioturbation, storm, dredging and other marina activities.

Recent studies of metal contamination in the San Francisco Bay identified previously contaminated sediments as a major source for some metals in the water column. Rivera-Duarte and Flegal calculated the total benthic fluxes of lead, ${ }^{3}$ silver, ${ }^{4}$ cadmium, cobalt, copper, nickel, and zinc ${ }^{5}$ using measured porewater concentrations and a flux equation that combines Fickian diffusion and an irrigation flux from bioturbation and mixing of the top sediments. They found that the relative benthic to fluvial inputs to the San Francisco Bay were metal specific. Lead inputs from the sediments were 30 to 930 times fluvial inputs. Silver release from the sediments near wastewater treatment outflows contributed about 2.5 times the input of the fluvial system for the entire San Francisco Bay. Benthic and fluvial inputs were similar for zinc, but nickel, cadmium, and copper showed small or negative fluxes from the sediments to the overlying waters. This approach is a useful metric to 


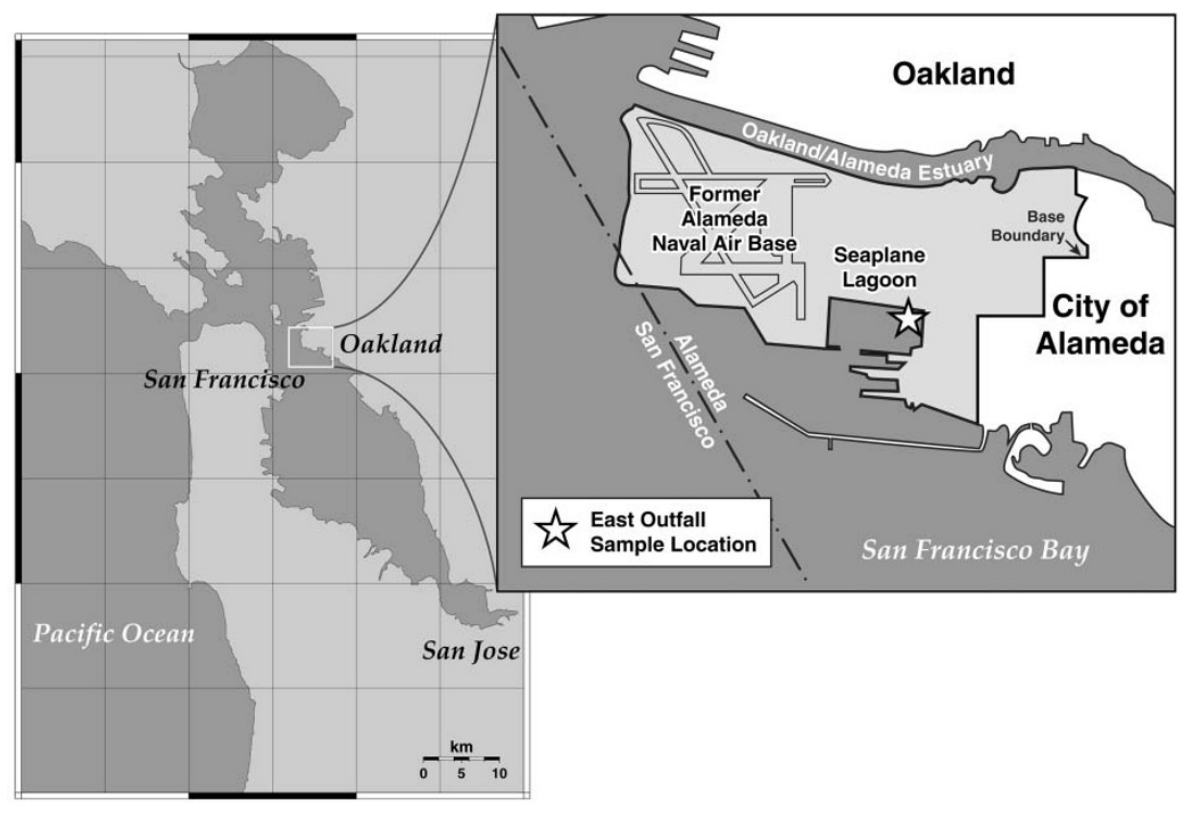

Fig. 1 Location map of field study. Star indicates general location where the sediment cores were sampled.

compare metal contamination sources in large watersheds, but it does not explicitly account for the geochemical reactions that control the porewater concentrations.

Important chemical controls on the flux of trace metals to the water column are the oxidation and reduction of sulfur and iron in surfacial estuarine sediments, as indicated by in situ measurement of trace metal fluxes across the sediment - water boundary in Gullmarsfjorden. ${ }^{6,7}$ In these studies, high fluxes of cadmium, copper, and zinc from the sediments to the overlying water in the oxygen-enhanced portion of the experiment were reversed when the overlying water went anoxic and trace metals were transferred to the sediments. However, the iron flux showed the opposite trend with a negative flux to the sediments during oxidation and positive flux to the water column as they became anoxic. The negative correlation between these trace metals and iron and the reported lack of correlation with carbonate flux suggests that cadmium, copper, and zinc are present in the sediments as sulfides which can be easily dissolved by oxygen-rich waters. The increase in dissolved iron as the sediments become anoxic represents the reductive dissolution of iron hydroxides that formed during the oxidation experiment. In situ measurements of this kind provide valuable insight into trace metal geochemistry, but final interpretation of the data lack confirmation of the reactions in the solid phases in the sediment.

Much of our knowledge of the solid chemical form of trace metals in reduced estuarine sediments has been derived indirectly from water analyses and from chemical extractions. Although there is ambiguity among studies, trace metal uptake in the sediments is often linked to iron sulfides such as pyrite $\left(\mathrm{FeS}_{2}\right)$ and monosulfides (amorphous $\mathrm{FeS}$ or mackinawite). For example, Kornicker and Morse $^{8}$ reported cadmium, manganese, and nickel sorption to pyrite in solution-based experiments. In estuarine sediments, copper and manganese have been identified as pyrite co-precipitates because they dissolved in the pyrite extraction. In contrast, cadmium, chromium, lead, and zinc are believed to be sequestered by other sulfides or oxides because a significant amount of these metals dissolved with less aggressive, non-pyrite extractions. ${ }^{9}$ Similarly trace metal sorption or co-precipitation with amorphous FeS or mackinawite have been observed. ${ }^{10,11} \mathrm{An}$ improved method to the use of chemical extractions is to determine trace metal bonding in sediments using synchrotron radiation X-ray absorption spectroscopy (XAS). This method is a unique molecular probe for complex materials because it is element specific, has relatively high sensitivity, does not require a vacuum, and is non-destructive. Thus, spectra for a number of elements can be directly measured on a bulk, untreated sediment samples with porewater present.

In this paper, we have examined the chemical processes that impact the fate of metal contaminated estuarine sediments if they are left undisturbed (in situ) or if they are dredged. We discuss the in situ geochemistry of metals (cadmium, chromium, copper, lead, manganese nickel, and zinc) with variation of depth in contaminated estuarine sediments from one site in the Seaplane Lagoon. We also discuss the geochemical processes responsible for the transfer of these metals from reduced contaminated estuarine sediments to oxygen-rich seawater by comparing in situ geochemistry with that of the oxidized sediments. To do this, we combine bulk sediment and porewater analyses, flow-through oxidation experiments, geochemical modeling, and X-ray absorption spectroscopy. Combination of the geochemical and spectroscopic data yields a more robust picture of the reactions that control the fate of trace metal contaminates in urban harbors and coastal sediments.

\section{Methods}

\subsection{Sample collection and analysis}

Between July 1997 and November 1998, a series of sediment cores were collected from the East Outfall Site, Seaplane Lagoon (Fig. 1). For the geochemical and spectroscopic results given here, we focus on $0.5 \mathrm{~m}$ Plexiglas push cores that were collected on July 10, 1997 and on November 10, 1997 within the same general location (GH-CC-SC2, GH-CC-SC4, GH-CC$\mathrm{SC} 7$, and $\mathrm{GH}-\mathrm{CC}-\mathrm{SC} 9$; referred to here as $\mathrm{SC} 2, \mathrm{SC} 4, \mathrm{SC} 7$, and SC9). Sediment cores were sectioned under argon and subsamples taken at $3 \mathrm{~cm}$ intervals from the center portion of the core to ensure no oxidation. Sediment compositions are reported for the push cores $\mathrm{SC} 2$ to $\mathrm{SC} 4$ and for deeper gravity cores to $1 \mathrm{~m}$ (GH-CC-C1, GH-CC-C2 and GH-CC-C3; referred to here as $\mathrm{C} 1, \mathrm{C} 2$, and $\mathrm{C} 3$ ). From core $\mathrm{SC} 4$, we extracted porewater for sulfur, chloride, trace and major element concentrations by centrifugation $(5000 \mathrm{rpm}$ for $60 \mathrm{~min}$ in argon-filled centrifuge tubes) and filtration (using $0.22 \mu \mathrm{m}$ polycarbonate filters), and we measured wet sediment $\mathrm{pH}$. From core SC2, we extracted porewater by Reeburgh-type 
pneumatic core squeezers in a nitrogen glove box for total phosphorus, sulfur and carbon concentrations. Synchrotron $\mathrm{X}$-ray absorption spectroscopy (XAS) data were collected from frozen samples stored in $\mathrm{N}_{2}$ (SC2, SC4, C1, C3) and from fresh, unfrozen sediments (SC7, SC9) within days of core recovery maintaining the oxic water column. Based on comparisons of fresh and frozen samples, freezing and thawing the sediments under controlled environments did not alter the metal chemistry.

\subsection{Sediment oxidation experiments}

Three samples of reduced Seaplane Lagoon sediment from core $\mathrm{SC} 4$ at $31.5 \mathrm{~cm}$ (SC4-11) were reacted with filtered, oxygen-rich seawater for 92 days to determine the net metal dissolution and changes in sediment metal coordination. The seawater $(\mathrm{pH}=$ 7.9) was collected offshore from the Pacific Ocean by Long's Marine Laboratory, University of California, Santa Cruz. The experiments were performed in well-mixed, flow-through reactors at room temperature. ${ }^{12}$ Reaction vessels and sample bottles were cleaned in a Class 100 clean room. Twenty samples were collected during the experiment and sample $\mathrm{pH}$ was measured immediately after the sample was collected. Samples for trace element analysis were acidified with ultra-pure nitric acid to prevent precipitation. Sample bottles were double bagged and stored in a laminar flow hood until they were analyzed in a Class 100 clean room. An identical control experiment with seawater and no sediment was also run to provide procedural blanks.

\subsection{Water analyses}

2.3.1. Trace metals. Seaplane Lagoon porewaters and output solutions from the oxidation experiments were analyzed for $\mathrm{Al}, \mathrm{Cd}, \mathrm{Cr}, \mathrm{Cu}, \mathrm{Fe}, \mathrm{Pb}, \mathrm{Mn}, \mathrm{Ni}$, and $\mathrm{Zn}$ using a HewlettPackard HP4500 inductively coupled plasma-mass spectrometer (ICP-MS). An isotope dilution method was used to measure the porewater $\mathrm{Cd}, \mathrm{Cr}, \mathrm{Cu}, \mathrm{Pb}, \mathrm{Ni}$, and $\mathrm{Zn}$ concentrations, by equilibrating the samples with a mixed enriched isotope spike $\left({ }^{111} \mathrm{Cd},{ }^{52} \mathrm{Cr},{ }^{65} \mathrm{Cu},{ }^{206} \mathrm{~Pb},{ }^{61} \mathrm{Ni},{ }^{67} \mathrm{Zn}\right)$ at temperature for $48 \mathrm{~h}$, and then concentrating the trace metals from the equilibrated porewater by precipitating $\mathrm{Mg}(\mathrm{OH})_{2}$ from seawater at $\mathrm{pH} 10$, which scavenges a number of trace metals. The precipitate was then carefully washed with $\mathrm{pH}$ 10 ultra-pure ammonium hydroxide solution to remove sea salts, and then dissolved in $2 \%$ ultra-pure nitric acid for trace metal analyses ${ }^{13}$ Because $\mathrm{Cd}$ and $\mathrm{Ni}$ were not concentrated on the $\operatorname{Mg}(\mathrm{OH})_{2}$ precipitate, the supernatant and washes were combined and concentrated using a Cetac Corporation DSX-100 system. Cd and $\mathrm{Ni}$ were run under normal plasma conditions, $\mathrm{Cr}$ and $\mathrm{Cu}$ were run under cool plasma conditions to reduce interference from $\mathrm{ArC}$ and $\mathrm{ArMg}$, and $\mathrm{Pb}$ and $\mathrm{Zn}$ were run under hot plasma conditions to enhance sensitivity at high masses. For all isotope dilution determinations, the error in the measured ratios was less than $10 \%$ and generally in the range of $1-4 \%$, and precision was $10-15 \%$ for $\mathrm{Cr}, \mathrm{Ni}, \mathrm{Cd}$ and $\mathrm{Pb}$; and $15-20 \%$ for $\mathrm{Cu}$ and $\mathrm{Zn}$.

For the porewater $\mathrm{Al}, \mathrm{Mn}$, and $\mathrm{Fe}$ analyses, aliquots of the saline porewater were diluted to 1 psu (practical salinity unit) with ultra-pure $2 \%$ nitric acid and spiked with Sc and Y as internal standards and run under normal plasma conditions. Calibration curves were made in a seawater reference standard (NASS-4) diluted to 1 psu to correct for matrix effects. Detection limits determined from the reproducibility of procedural blanks were $1 \mathrm{ng} \mathrm{g}^{-1}$ for $\mathrm{Al}, 0.1 \mathrm{ng} \mathrm{g}^{-1}$ for $\mathrm{Mn}$, and $100 \mathrm{ng} \mathrm{g}^{-1}$ for $\mathrm{Fe}$, and precision was generally less than $5-10 \%$.

Filtered output samples from the oxidation experiments were concentrated 5 to 10 times using a Cetac Corporation DSX-100 system, spiked with $\mathrm{Sc}, \mathrm{Y}, \mathrm{In}, \mathrm{Tb}$, and Bi internal standards to correct for matrix effects and instrument drift, and run under hot plasma conditions. Calibration curves were made in a series of standards in 2\% ultra-pure nitric acid. Reported errors include both measurement and calibration uncertainties. Detection limits were determined by processing ion-exchange resin beads through the DSX-100 chemistry under the same conditions as the output samples. No significant differences were seen in different batches of resin. Accuracy was measured against metal concentrations in two seawater reference standards, NASS-4 and CASS-3.

2.3.3. Major elements, sulfur, chloride, and carbon analyses. Total dissolved $\mathrm{Al}, \mathrm{Ca}, \mathrm{Fe}, \mathrm{K}, \mathrm{Mg}, \mathrm{Mn}, \mathrm{Na}, \mathrm{P}, \mathrm{S}$, and Si were analyzed by a Fisons Instruments (Model 3560) inductively coupled plasma-atomic emission spectrometer against multi-point calibration curves in distilled and deionized water. The reproducibility of this technique was better than $2 \%$. Sulfur speciation and concentrations were determined by ion chromatography (Beckman 421A controller, a LDC Milton Roy Conducto Monitor III conductivity detector, and a Waters $4.6 \times 150 \mathrm{~mm}$ IC-Pak Anion HC column) against multi-point calibration curves. Samples were injected in a helium-purged, $5 \mathrm{mM}$ sodium phosphate solution. Detection limit was $5 \mathrm{mg} \mathrm{L}^{-1}$ for each sulfur species, and precision and accuracy were better than $10 \%$. Chloride concentrations were determined using an ion-specific probe against a multi-point $\mathrm{NaCl}$ calibration curve in distilled and deionized water. The detection limit was $10 \mathrm{ng} \mathrm{g}^{-1}$, and precision and accuracy were better than $10 \%$. Dissolved carbon analyses were made with an infrared carbon analyzer (O. I. Analytical TOC 700). Total inorganic carbon (TIC) and total organic carbon (TOC) were measured in sequence by first acidifying the sample to $\mathrm{pH}<4$, heating it to $100{ }^{\circ} \mathrm{C}$, and trapping and detecting the evolved $\mathrm{CO}_{2}$. The dissolved organic carbon in the sample was then oxidized with sodium persulfate at $100{ }^{\circ} \mathrm{C}$ and the evolved $\mathrm{CO}_{2}$ was trapped and detected. Total carbon (TC) was measured directly by combining the TIC and TOC methods into a single step.

\subsection{Bulk sediment chemistry and mineralogy}

2.4.1. Sediment digestion. The chemical depth profiles were determined for cores SC2-4 and C1-3 from sediment samples digested with acid UA2 solutions (mixture of concentrated HF and $\mathrm{HCl}$ from Unisolv, Inc.) in a microwave and neutralized and stabilized with UNS2A/2B solutions (mixtures of $\mathrm{H}_{3} \mathrm{BO}_{3}$, TETA and EDTA from Unisolv, Inc.). Reported Al, Ca, Cd, $\mathrm{Co}, \mathrm{Cr}, \mathrm{Cu}, \mathrm{Fe}, \mathrm{Mg}, \mathrm{Mn}, \mathrm{Ni}, \mathrm{Pb}, \mathrm{S}$, and $\mathrm{Zn}$ concentrations were analyzed by inductively coupled plasma-atomic emission spectrometry. Analysis protocol adheres to EPA SW-846 Method 6010A augmented to include all of the elements listed above. A scandium spike was added to all samples to correct for viscosity effects resulting from the high silica content of these sediments and instrument drift. Detection limits and analytical reproducibility are reported in the data. The quartz content prevented recovery of silica concentrations because silica did not stay in solution. The external standard was the NIST Buffalo River sediment.

2.4.2. X-ray diffraction. Sediment mineralogy was determined by X-ray diffraction (XRD) on freeze dried and ground sediment samples from cores SC2-4 and C1-3. Data were collected from random orientation powder samples with a Scintag PAD V instrument using a $\mathrm{Cu}-\mathrm{K} \alpha$ source at $45 \mathrm{kV}$ and $35 \mathrm{~mA}$ from 2 to $92^{\circ} 2 \theta$ in $0.02^{\circ}$ steps. XRD cannot detect amorphous solids or minerals that are present at $<2 \mathrm{wt} \%$. For a few samples, XRD spectra were collected on air-dried and ethylene glycol-saturated sediments to separate some of the diagnostic clay peaks (e.g., smectite from chlorite). Reported mineral abundance is estimated by assigning minimum XRD detection limits to the trace mineral components $(\sim 2 \mathrm{wt} \%)$. 


\subsection{XAS data collection and analysis}

X-ray absorption spectroscopy (XAS), including X-ray absorption near-edge structure (XANES) and extended X-ray absorption fine structure (EXAFS) analyses, were used to characterize the speciation and bonding of metals in sediments from cores. Fluorescence spectra were collected at Stanford Synchrotron Radiation Laboratory (SSRL) on wiggler beamlines 4-1 and 4-3 using either a 13-element Ge array detector, a 4-element Ge array detector, or a Lytle detector. Either a $\mathrm{Si}(111)$ or $\mathrm{Si}(220)$ monochromator crystal was used, depending on which crystal produced the higher quality spectra for a given element, and detuned $50-70 \%$ of maximum intensity to minimize higherorder harmonic reflections. XANES spectra for chrominum and manganese were collected with a $\mathrm{Si}(220)$ crystal to achieve higher energy resolution. Spectra were collected at ambient temperature with the sample in an helium atmosphere to prevent oxidation of sensitive elements. For a given element, energy was calibrated using a reference foil spectrum. Absorption spectra for crystalline reference compounds and fresh precipitates for each element were collected and analyzed for comparison to sediment spectra.

XANES spectra were used to identify oxidation states for chrominum and manganese and to qualitatively identify sediment components. Background-subtracted XANES spectra were normalized to maximum absorption and first-deriviative spectra were fit with linear combination of reference spectra using the program DATFIT (G. George, ref. 62). EXAFS spectra were quantitatively analyzed using EXAFSPAK ${ }^{14}$ and FEFF $^{15}$ according to methods described in O'Day et al. ${ }^{16}$ and Carroll et al. ${ }^{17}$ Debye-Waller factors $\left(\sigma^{2}\right)$ were fixed on values determined from fits to reference spectra of compounds of similar structure and composition to sediment components. For trace metals $(\mathrm{Cd}, \mathrm{Zn}, \mathrm{Cr}, \mathrm{Pb}$, and $\mathrm{Mn})$, proportions of sulfide and oxide components in the sediment spectra were estimated based on the relative proportions of first-shell oxygen and sulfur backscatterers. For these spectra, detection of a unique bonding site is estimated at about $10-15$ atom $\%$ of the total element signal. For iron, the sulfide and oxide components were quantitatively determined based on integrated areas of least-squares fits. Fit areas were calibrated using spectra of standard mixtures of pyrite (commercial), nontronite (The Clay Minerals Society, Standard NAu-1), and illite (The Clay Minerals Society, Standard IMt-1) in a ground quartz matrix at 5 atom $\%$ total iron to simulate sediment concentrations. Spectra of the reference mixtures were collected in fluorescence at room temperature at SSRL on beamlines 2-3 and 4-3. Based on sensitivity tests with known concentrations, the proportion of pyrite in these sediments can be determined to better than $\pm 5 \%$ of the total iron in the sample (see ref. 18).

\subsection{Geochemical modeling of porewaters}

The aqueous geochemistry was modeled thermodynamically for sulfide, carbonate, oxide/hydroxide, and silicate saturation and aqueous complexation versus depth with the Geochemist's Workbench geochemical code ${ }^{19}$ and SUPCRT92 database ${ }^{20}$ modified to include aqueous $\mathrm{Cd}-, \mathrm{Cr}-, \mathrm{Fe}-, \mathrm{Mn}-, \mathrm{Ni}-, \mathrm{Pb}$, and $\mathrm{Zn}$-sulfide species, and $\mathrm{Zn}-, \mathrm{Cd}-$, and $\mathrm{Pb}$-carbonate and hydroxide phases (Table 1). Activity coefficients were calculated from the extended Debye-Hückel method, which is valid to ionic strengths of about $3 \mathrm{~mol} \mathrm{~kg}{ }^{-1}$. For these calculations, we used field temperature, porewater trace and major element concentrations with dissolved sulfur as $\mathrm{HS}^{-}$, and sediment $\mathrm{pH}$ from core $\mathrm{SC} 4$. Alkalinity as $\mathrm{HCO}_{3}{ }^{-}$was calculated as a function of depth for core SC4 from a linear regression of the inorganic-carbon concentration measured in core SC2 data. For the surface sediments at $1.5 \mathrm{~cm}$, alkalinity is calculated from measured $\mathrm{pH}$ and atmospheric $\mathrm{CO}_{2}$, because the linear
Table 1 Thermodynamic equilibria and constants used in the geochemical modeling of the porewater chemistry in the Seaplane Lagoon sediments

\begin{tabular}{|c|c|c|}
\hline & $\begin{array}{l}\log K \\
\left(25^{\circ} \mathrm{C}\right)\end{array}$ & $\mathrm{Re}$ \\
\hline $\mathrm{Al}(\mathrm{OH})_{3}($ gibbsite $)+3 \mathrm{H}^{+} \rightarrow \mathrm{Al}^{3+}$ & 7.76 & 38 \\
\hline $\mathrm{AlOOH}($ boehmite $)+3 \mathrm{H}^{+} \rightarrow \mathrm{Al}^{3+}+2 \mathrm{H}_{2} \mathrm{O}$ & 7.56 & 38 \\
\hline $\mathrm{CaCO}_{3}$ (calcite) $\rightarrow \mathrm{Ca}^{2+}+\mathrm{CO}_{3}{ }^{2-}$ & -8.48 & 39 \\
\hline $\mathrm{CaMg}\left(\mathrm{CO}_{3}\right)_{2}$ (dolomite $) \rightarrow \mathrm{Ca}^{2+}+\mathrm{Mg}^{2+}+2 \mathrm{CO}_{3}{ }^{2-}$ & -18.14 & 39 \\
\hline $\mathrm{CaSO}_{4} \cdot 2 \mathrm{H}_{2} \mathrm{O}($ gypsum $) \rightarrow \mathrm{Ca}^{2+}+\mathrm{SO}_{4}^{2-}+2 \mathrm{H}_{2} \mathrm{O}$ & -4.48 & 40 \\
\hline $\mathrm{Cd}^{2+}+\mathrm{H}_{2} \mathrm{O} \rightarrow \mathrm{CdOH}^{+}+\mathrm{H}^{+}$ & -10.08 & 41 \\
\hline $\mathrm{Cd}^{2+}+2 \mathrm{H}_{2} \mathrm{O} \rightarrow \mathrm{Cd}(\mathrm{OH})_{2}{ }^{0}+2 \mathrm{H}^{+}$ & -20.34 & 41 \\
\hline $\mathrm{Cd}^{2+}+3 \mathrm{H}_{2} \mathrm{O} \rightarrow \mathrm{Cd}(\mathrm{OH})_{3}{ }^{-1}+3 \mathrm{H}^{+}$ & -33.29 & 41 \\
\hline $\mathrm{Cd}^{2+}+4 \mathrm{H}_{2} \mathrm{O} \rightarrow \mathrm{Cd}(\mathrm{OH})_{4}{ }^{2-}+4 \mathrm{H}^{+}$ & -47.33 & 41 \\
\hline $\mathrm{Cd}^{2+}+\mathrm{Cl}^{-} \rightarrow \mathrm{CdCl}^{+}$ & 1.97 & 42 \\
\hline $\mathrm{Cd}^{2+}+2 \mathrm{Cl}^{-} \rightarrow \mathrm{CdCl}_{2}(\mathrm{aq})$ & 2.59 & 42 \\
\hline $\mathrm{Cd}^{2+}+3 \mathrm{Cl}^{-} \rightarrow \mathrm{CdCl}_{3}^{-}$ & 2.34 & 42 \\
\hline $\mathrm{Cd}^{2+}+4 \mathrm{Cl}^{-} \rightarrow \mathrm{CdCl}_{4}^{2-}$ & -1.46 & 42 \\
\hline $\mathrm{Cd}^{2+}+\mathrm{CO}_{3}^{2-} \rightarrow \mathrm{CdCO}_{3}{ }^{2}$ & 3.00 & 43 \\
\hline $\mathrm{Cd}^{2+}+2 \mathrm{CO}_{3}{ }^{2-} \rightarrow \mathrm{Cd}\left(\mathrm{CO}_{3}\right)_{2}{ }^{2-}$ & 6.40 & 43 \\
\hline $\mathrm{Cd}^{2+}+\mathrm{CO}_{3}^{2-}+\mathrm{H}^{+} \rightarrow \mathrm{CdHCO}_{3}^{+}$ & 11.83 & 43 \\
\hline $\mathrm{Cd}^{2+}+\mathrm{SO}_{4}^{2-} \rightarrow \mathrm{CdSO}_{4}{ }^{20}$ & -0.003 & 44 \\
\hline $\mathrm{CdHS}^{+} \rightarrow \mathrm{HS}^{-}+\mathrm{Cd}^{2+}$ & -9.02 & $45^{a}$ \\
\hline $\mathrm{Cd}(\mathrm{HS})_{2} \rightarrow 2 \mathrm{HS}^{-}+\mathrm{Cd}^{2+}$ & -16.53 & $45^{a}$ \\
\hline $\mathrm{Cd}(\mathrm{OH})_{2}($ beta $)+2 \mathrm{H}^{+} \rightarrow \mathrm{Cd}^{2+}+2 \mathrm{H}_{2} \mathrm{O}$ & 13.64 & 41 \\
\hline $\mathrm{CdS}+\mathrm{H}^{+} \rightarrow \mathrm{HS}^{-}+\mathrm{Cd}^{2+}$ & -15.91 & 44 \\
\hline $\mathrm{CdSO}_{4}$ (anglesite) $\rightarrow \mathrm{Cd}^{2+}+\mathrm{SO}_{4}^{2-}$ & -0.11 & 44 \\
\hline $\mathrm{CdCO}_{3}$ (otavite) $\rightarrow \mathrm{Cd}^{2+}+\mathrm{CO}_{3}^{2-}$ & -12.1 & 43 \\
\hline $\mathrm{CdO}($ monteponite $)+2 \mathrm{H}^{+} \rightarrow \mathrm{Cd}^{2+}+\mathrm{H}_{2} \mathrm{O}$ & 15.1 & 46 \\
\hline $\mathrm{Cr}^{3+}+\mathrm{Cl}^{-} \rightarrow \mathrm{CrCl}^{2+}$ & 7.60 & 47 \\
\hline $\mathrm{Cr}^{3+}+2 \mathrm{Cl}^{-} \rightarrow \mathrm{CrCl}_{2}^{-}$ & 7.91 & 47 \\
\hline $\mathrm{CrHS}^{2+} \rightarrow \mathrm{HS}^{-}+\mathrm{Cr}^{3+}$ & -9.88 & $45^{a}$ \\
\hline $\begin{array}{l}\mathrm{CrS}+2 \mathrm{H}^{+}+0.25 \mathrm{O}_{2}(\mathrm{aq}) \rightarrow 0.5 \mathrm{H}_{2} \mathrm{O}+ \\
\mathrm{Cr}^{3+}+\mathrm{HS}^{-}\end{array}$ & 31.35 & 47 \\
\hline $\mathrm{Cr}_{2} \mathrm{O}_{3}$ (eskolaite) $+6 \mathrm{H}^{+} \rightarrow 3 \mathrm{H}_{2} \mathrm{O}+2 \mathrm{Cr}^{3+}$ & 7.64 & 44 \\
\hline $\mathrm{Cu}^{2+}+\mathrm{Cl}^{-} \rightarrow \mathrm{CuCl}^{+}$ & 0.40 & 42 \\
\hline $\mathrm{Cu}^{2+}+2 \mathrm{Cl}^{-} \rightarrow \mathrm{CuCl}_{2}(\mathrm{aq})$ & -0.69 & 42 \\
\hline $\mathrm{Cu}^{2+}+3 \mathrm{Cl}^{-} \rightarrow \mathrm{CuCl}_{3}^{-}$ & -2.29 & 42 \\
\hline $\mathrm{Cu}^{2+}+4 \mathrm{Cl}^{-} \rightarrow \mathrm{CuCl}_{4}^{2-}$ & -4.94 & 42 \\
\hline $\mathrm{CuS}($ covellite $)+\mathrm{H}^{+} \rightarrow \mathrm{HS}^{-}+\mathrm{Cu}^{2+}$ & -22.83 & 39 \\
\hline $\begin{array}{l}\mathrm{CuFeS}_{2}(\text { chalcopyrite })+2 \mathrm{H}^{+} \rightarrow 2 \mathrm{HS}^{-}+ \\
\mathrm{Fe}^{2+}+\mathrm{Cu}^{2+}\end{array}$ & -32.56 & 39 \\
\hline $\begin{array}{l}\mathrm{Cu}_{2} \mathrm{CO}_{3}(\mathrm{OH})_{2}(\text { malachite })+2 \mathrm{H}^{+} \rightarrow 2 \mathrm{H}_{2} \mathrm{O}+ \\
\mathrm{CO}_{3}^{2-}+2 \mathrm{Cu}^{2+}\end{array}$ & -4.40 & 39 \\
\hline $\mathrm{CuO}($ tenorite $)+2 \mathrm{H}^{+} \rightarrow \mathrm{Cu}^{2+}+\mathrm{H}_{2} \mathrm{O}$ & 7.66 & 39 \\
\hline $\mathrm{FeHS}^{+} \rightarrow \mathrm{HS}^{-}+\mathrm{Fe}^{2+}$ & -5.52 & $48^{a}$ \\
\hline$(\mathrm{Fe})_{2} \mathrm{HS}^{3+} \rightarrow \mathrm{HS}^{-}+2 \mathrm{Fe}^{2+}$ & -10.02 & $48^{a}$ \\
\hline$(\mathrm{Fe})_{3} \mathrm{HS}^{5+} \rightarrow \mathrm{HS}^{-}+3 \mathrm{Fe}^{2+}$ & -15.30 & $48^{a}$ \\
\hline $\mathrm{Fe}^{2+}+\mathrm{Cl}^{-} \rightarrow \mathrm{FeCl}^{+}$ & -0.16 & 42 \\
\hline $\mathrm{Fe}^{2+}+2 \mathrm{Cl}^{-} \rightarrow \mathrm{FeCl}_{2}(\mathrm{aq})$ & -8.17 & 42 \\
\hline $\mathrm{Fe}^{3+}+\mathrm{Cl}^{-} \rightarrow \mathrm{FeCl}^{2+}$ & 1.47 & 42 \\
\hline $\mathrm{Fe}^{3+}+2 \mathrm{Cl}^{-} \rightarrow \mathrm{FeCl}_{2}^{+}$ & 2.13 & 49 \\
\hline $\mathrm{Fe}^{3+}+4 \mathrm{Cl}^{-} \rightarrow \mathrm{FeCl}_{4}^{-}$ & -0.79 & 49 \\
\hline $\begin{array}{l}\mathrm{FeS}_{2}(\text { pyrite })+\mathrm{H}_{2} \mathrm{O} \rightarrow \mathrm{Fe}^{2+}+2 \mathrm{HS}^{2-}+ \\
0.5 \mathrm{O}_{2}(\mathrm{aq})\end{array}$ & -59.23 & 39 \\
\hline $\mathrm{FeS}($ pyrrhotite $)+\mathrm{H}^{+} \rightarrow \mathrm{HS}^{-}+\mathrm{Fe}^{2+}$ & -3 & 39 \\
\hline $\mathrm{FeCO}_{3}$ (siderite) $\rightarrow \mathrm{Fe}^{2+}+\mathrm{CO}_{3}^{2-}$ & -10.52 & 39 \\
\hline $\begin{array}{l}\mathrm{FeOOH}(\text { goethite })+2 \mathrm{H}^{+} \rightarrow \mathrm{Fe}^{2+}+ \\
\quad 1.5 \mathrm{H}_{2} \mathrm{O}+0.25 \mathrm{O}_{2}(\mathrm{aq})\end{array}$ & -7.96 & 40 \\
\hline $\begin{array}{c}\mathrm{Na}_{0.33} \mathrm{Fe}_{2} \mathrm{Al}_{0.33} \mathrm{Si}_{3.67} \mathrm{O}_{10}(\mathrm{OH})_{2}(\text { Na-nontronite })+ \\
5.32 \mathrm{H}^{+} \rightarrow 2 \mathrm{Fe}^{2+}+0.33 \mathrm{Al}^{3+}+\mathrm{O} .5 \mathrm{O}_{2}(\mathrm{aq})+ \\
0.33 \mathrm{Na}^{+}+3.67 \mathrm{SiO}_{2}+3.66 \mathrm{H}_{2} \mathrm{O}\end{array}$ & -28.51 & 50 \\
\hline $\begin{array}{c}\mathrm{Mg}_{5} \mathrm{Al}_{2} \mathrm{Si}_{3} \mathrm{O}_{10}(\mathrm{OH})_{8}(7 \AA \text { chlorite })+ \\
16 \mathrm{H}^{+} \rightarrow 2 \mathrm{Al}^{3+}+ \\
12 \mathrm{H}_{2} \mathrm{O}+3 \mathrm{SiO}_{2}(\mathrm{aq})+5 \mathrm{Mg}^{2+}\end{array}$ & 70.61 & 39 \\
\hline $\mathrm{Mn}^{2+}+\mathrm{Cl}^{-} \rightarrow \mathrm{MnCl}^{+}$ & 0.14 & 42 \\
\hline $\mathrm{Mn}^{2+}+3 \mathrm{Cl}^{-} \rightarrow \mathrm{MnCl}_{3}^{-}$ & -0.77 & 44 \\
\hline $\mathrm{MnHS}^{+} \rightarrow \mathrm{HS}^{-}+\mathrm{Mn}^{2+}$ & -5.00 & $48^{a}$ \\
\hline $\mathrm{S}^{3+} \rightarrow \mathrm{HS}^{-}+2 \mathrm{Mn}^{2+}$ & -9.55 & $48^{a}$ \\
\hline$(\mathrm{Mn})_{3} \mathrm{HS}^{5+} \rightarrow \mathrm{HS}^{-}+3 \mathrm{Mn}^{2+}$ & -13.63 & $48^{a}$ \\
\hline $\mathrm{MnS}($ alabandite $)+\mathrm{H}^{+} \rightarrow \mathrm{HS}^{-}+\mathrm{Mn}^{2+}$ & -0.05 & 39 \\
\hline $\mathrm{MnCO}_{3}($ rhodochrosite $) \rightarrow \mathrm{Mn}^{2+}+\mathrm{CO}_{3}{ }^{2-}$ & -10.52 & 39 \\
\hline $\mathrm{Ni}(\mathrm{OH})_{2}+2 \mathrm{H}^{+} \rightarrow \mathrm{Ni}^{2+}+2 \mathrm{H}_{2} \mathrm{O}$ & 7.64 & 44 \\
\hline $\mathrm{Ni}^{2+}+\mathrm{Cl}^{-} \rightarrow \mathrm{NiCl}^{+}$ & -1.00 & 42 \\
\hline $\mathrm{NiCO}_{3} \rightarrow \mathrm{CO}_{3}{ }^{2-}+\mathrm{Ni}^{2+}$ & -6.82 & 44 \\
\hline $\mathrm{NiHS}^{+} \rightarrow \mathrm{HS}^{-}+\mathrm{Ni}^{2+}$ & -5.29 & $48^{a}$ \\
\hline$(\mathrm{Ni})_{2} \mathrm{HS}^{3+} \rightarrow \mathrm{HS}^{-}+2 \mathrm{Ni}^{2+}$ & -9.82 & $48^{a}$ \\
\hline$+{ }^{+} \rightarrow \mathrm{HS}^{-}+3$ & -13.65 & $48^{a}$ \\
\hline
\end{tabular}


Table 1 Thermodynamic equilibria and constants used in the geochemical modeling of the porewater chemistry in the Seaplane Lagoon sediments (continued)

\begin{tabular}{|c|c|c|}
\hline & $\begin{array}{l}\log K \\
\left(25^{\circ} \mathrm{C}\right)\end{array}$ & Ref. \\
\hline $\begin{array}{l}\mathrm{NiS}_{2}(\text { vaesite })+\mathrm{H}_{2} \mathrm{O} \rightarrow \mathrm{Ni}^{2+}+2 \mathrm{HS}^{-} \\
\quad+0.5 \mathrm{O}_{2}(\mathrm{aq})\end{array}$ & -61.34 & 39 \\
\hline $\mathrm{NiS}($ millerite $)+\mathrm{H}^{+} \rightarrow \mathrm{HS}^{-}+\mathrm{Ni}^{2+}$ & -8.03 & 51 \\
\hline $\mathrm{PbS}($ galena $)+\mathrm{H}^{+} \rightarrow \mathrm{HS}^{-}+\mathrm{Pb}^{2+}$ & -14.85 & 44 \\
\hline $\mathrm{Pb}^{2+}+\mathrm{H}_{2} \mathrm{O} \rightarrow \mathrm{PbOH}^{+}+\mathrm{H}^{+}$ & -7.7 & 52 \\
\hline $\mathrm{Pb}^{2+}+2 \mathrm{H}_{2} \mathrm{O} \rightarrow \mathrm{Pb}(\mathrm{OH})_{2}+2 \mathrm{H}^{+}$ & -17.09 & 52 \\
\hline $\mathrm{Pb}^{2+}+3 \mathrm{H}_{2} \mathrm{O} \rightarrow \mathrm{Pb}(\mathrm{OH})_{3}^{-}+3 \mathrm{H}^{+}$ & -28.09 & 52 \\
\hline $\mathrm{Pb}^{2+}+\mathrm{Cl}^{-} \rightarrow \mathrm{Pb} \mathrm{Cl}^{+}$ & 1.44 & 42 \\
\hline $\mathrm{Pb}^{2+}+2 \mathrm{Cl}^{-} \rightarrow \mathrm{PbCl}_{2}(\mathrm{aq})$ & 2.00 & 42 \\
\hline $\mathrm{Pb}^{2+}+3 \mathrm{Cl}^{-} \rightarrow \mathrm{Pb} \mathrm{Cl}_{3}^{-}$ & 1.69 & 42 \\
\hline $\mathrm{Pb}^{2+}+4 \mathrm{Cl}^{-} \rightarrow \mathrm{Pb} \mathrm{Cl}_{4}^{2-}$ & 1.43 & 42 \\
\hline $\mathrm{Pb}^{2+}+\mathrm{CO}_{3}^{2-} \rightarrow \mathrm{PbCO}_{3}$ & 6.58 & 53 \\
\hline $\mathrm{Pb}^{2+}+2 \mathrm{CO}_{3}^{2-} \rightarrow \mathrm{Pb}\left(\mathrm{CO}_{3}\right)^{2-}$ & 9.40 & 53 \\
\hline $\mathrm{PbCO}_{3}$ (cerussite) $\rightarrow \mathrm{Pb}^{2+}+\mathrm{CO}_{3}^{2-}$ & -13.54 & 20 \\
\hline $\begin{array}{l}\mathrm{Pb}_{3}\left(\mathrm{CO}_{3}\right)_{2}(\mathrm{OH})_{2} \text { (hydrocerussite) }+2 \mathrm{H}^{+} \\
\quad \rightarrow 2 \mathrm{CO}_{3}^{2-}+3 \mathrm{~Pb}^{2+}+2 \mathrm{H}_{2} \mathrm{O}\end{array}$ & -18.81 & 52 \\
\hline $\mathrm{PbSO}_{4}($ anglesite $) \rightarrow \mathrm{Pb}^{2+}+\mathrm{SO}_{4}^{2-}$ & -7.85 & 39 \\
\hline $\mathrm{PbHS}^{+} \rightarrow \mathrm{HS}^{-}+\mathrm{Pb}^{2+}$ & -8.62 & $45^{a}$ \\
\hline $\mathrm{Pb}(\mathrm{HS})_{2} \rightarrow 2 \mathrm{HS}^{-}+\mathrm{Pb}^{2+}$ & -16.43 & $45^{a}$ \\
\hline $\mathrm{SiO}_{2}$ (quartz) $\rightarrow \mathrm{SiO}_{2}$ (aq) & -4.0 & 39 \\
\hline $\mathrm{SiO}_{2}(\alpha$-cristobalite $) \rightarrow \mathrm{SiO}_{2}(\mathrm{aq})$ & -3.45 & 39 \\
\hline $\mathrm{SiO}_{2}$ (am. si.) $\rightarrow \mathrm{SiO}_{2}(\mathrm{aq})$ & -2.71 & 39 \\
\hline $\mathrm{Zn}^{2+}+\mathrm{H}_{2} \mathrm{O} \rightarrow \mathrm{ZnOH}^{+}+\mathrm{H}^{+}$ & -8.96 & 54 \\
\hline $\mathrm{Zn}^{2+}+2 \mathrm{H}_{2} \mathrm{O} \rightarrow \mathrm{Zn}(\mathrm{OH})_{2}{ }^{0}+2 \mathrm{H}^{+}$ & -28.04 & 44 \\
\hline $\mathrm{Zn}^{2+}+3 \mathrm{H}_{2} \mathrm{O} \rightarrow \mathrm{Zn}(\mathrm{OH})_{3}^{-}+3 \mathrm{H}^{+}$ & -28.83 & 44 \\
\hline $\mathrm{Zn}^{2+}+4 \mathrm{H}_{2} \mathrm{O} \rightarrow \mathrm{Zn}(\mathrm{OH})_{4}^{-}+4 \mathrm{H}^{+}$ & -41.61 & 44 \\
\hline $\mathrm{Zn}^{2+}+\mathrm{Cl}^{-} \rightarrow \mathrm{ZnCl}^{+}$ & 1.99 & 42 \\
\hline $\mathrm{Zn}^{2+}+2 \mathrm{Cl}^{-} \rightarrow \mathrm{ZnCl}_{2}(\mathrm{aq})$ & 2.51 & 42 \\
\hline $\mathrm{Zn}^{2+}+3 \mathrm{Cl}^{-} \rightarrow \mathrm{ZnCl}_{3}^{-}$ & -0.02 & 42 \\
\hline $\mathrm{Zn}^{2+}+\mathrm{CO}_{3}^{2-}+\mathrm{H}^{+} \rightarrow \mathrm{ZnHCO}_{3}^{+}$ & 8.91 & 54 \\
\hline $\mathrm{Zn}^{2+}+\mathrm{CO}_{3}^{2-} \rightarrow \mathrm{ZnCO}_{3}{ }^{2}$ & 3.9 & 55 \\
\hline $\mathrm{Zn}^{2+}+\mathrm{SO}_{4}^{2-} \rightarrow \mathrm{ZnSO}_{4}^{00}$ & -0.026 & 44 \\
\hline $\mathrm{Zn}_{2} \mathrm{~S}_{3}{ }^{2-}+3 \mathrm{H}^{+} \rightarrow 3 \mathrm{HS}^{-}+2 \mathrm{Zn}^{2+}$ & -1.07 & $56^{a}$ \\
\hline $\mathrm{Zn}_{4} \mathrm{~S}_{6}^{4-}+6 \mathrm{H}^{+} \rightarrow 6 \mathrm{HS}^{-}+4 \mathrm{Zn}^{2+}$ & -5.22 & $56^{a}$ \\
\hline $\mathrm{ZnS}($ sphalerite $)+\mathrm{H}^{+} \rightarrow \mathrm{HS}^{-}+\mathrm{Zn}^{2+}$ & -11.44 & 39 \\
\hline $\mathrm{Zn}(\mathrm{OH})_{2}(\beta)+2 \mathrm{H}^{+} \rightarrow \mathrm{Zn}^{2+}+2 \mathrm{H}_{2} \mathrm{O}$ & 11.93 & 44 \\
\hline $\mathrm{Zn}(\mathrm{OH})_{2}(\varepsilon)+2 \mathrm{H}^{+} \rightarrow \mathrm{Zn}^{2+}+2 \mathrm{H}_{2} \mathrm{O}$ & 11.66 & 44 \\
\hline $\mathrm{Zn}(\mathrm{OH})_{2}(\gamma)+2 \mathrm{H}^{+} \rightarrow \mathrm{Zn}^{2+}+2 \mathrm{H}_{2} \mathrm{O}$ & 11.88 & 44 \\
\hline $\mathrm{ZnSO}_{4}$ (solid) $\rightarrow \mathrm{Zn}^{2+}+\mathrm{SO}_{4}^{2-}$ & 3.55 & 44 \\
\hline $\mathrm{ZnCO}_{3}$ (smithsonite) $\rightarrow \mathrm{Zn}^{2+}+\mathrm{CO}_{3}{ }^{2-}$ & -9.87 & 20 \\
\hline $\mathrm{Zn}_{5}(\mathrm{OH})_{6}\left(\mathrm{CO}_{3}\right)_{2}$ (hydrozincite) $+6 \mathrm{H}^{+}$ & 9.65 & 57 \\
\hline
\end{tabular}

$\rightarrow 5 \mathrm{Zn}^{2+}+2 \mathrm{CO}_{3}^{2-}+6 \mathrm{H}_{2} \mathrm{O}$

${ }^{a}$ Experimental values extrapolated to $I=0$.

extrapolation yielded negative values. The solution was charge balanced by adjusting the chloride concentration.

\section{Results}

\subsection{Depth profiles of the porewater chemistry}

We report the porewater trace and major element, chloride, sulfur, and $\mathrm{pH}$ for core SC4 and the porewater total phosphorus, carbon, inorganic carbon, and organic carbon for core SC2 in Fig. 2 and in Tables 2 and 3. There are distinct trends in the porewater composition with depth in core SC4. Calcium, magnesium, potassium, sodium, chloride, and sulfide concentrations increase with depth to $25.5 \mathrm{~cm}$ and remain constant at greater depths. Aluminium concentrations are quite low and constant (with the exception of one outlying data point). Silica concentrations increase by about two times from surface sediments to a depth of $4.5 \mathrm{~cm}$, and remain constant at greater depths. Iron concentrations were detected only at depths above $4.5 \mathrm{~cm}$. Cadmium, chromium, and lead concentrations increase with depth following similar trends observed for their sediment concentrations. Nickel concentrations show a slight decrease with depth. Copper, manganese, and zinc depth profiles are more complicated. Manganese concentrations decrease to minimum at a depth of $4.5 \mathrm{~cm}$, then increase to a maximum
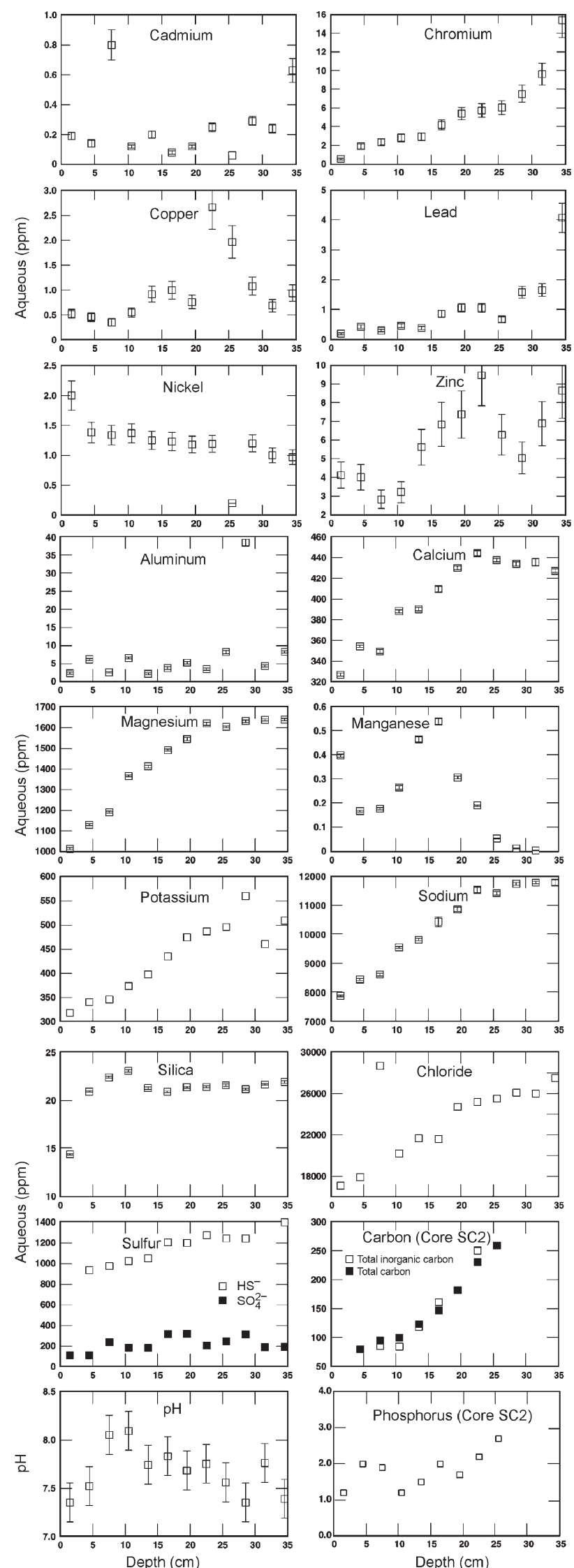

Fig. 2 Chemical composition of porewaters extracted from core SC4. Dissolved carbon data is from core SC2. Both cores were collected on July 10, 1997.

at a depth of $16.5 \mathrm{~cm}$, and then decrease at greater depths. Zinc and copper concentrations increase to maximum at a depth of $22.5 \mathrm{~cm}$, decrease between 22.5 and $28.5-31.5 \mathrm{~cm}$, and 
Table 2 Porewater trace- and major-elements extracted from Seaplane Lagoon core SC4 (July 10, 1998). Calcium, iron, potassium, magnesium, manganese, sodium, and silica were measured by ICP-AES. Aluminium, cadmium, chromium, copper, iron, lead, manganese, nickel, and zinc were measured by ICP-MS. Uncertainty for potassium was not reported

\section{ICP-AES}

\begin{tabular}{lllllllll}
\hline Sample ID & Depth/cm & Ca $(\mathrm{ppm})$ & Fe $(\mathrm{ppm})$ & $\mathrm{K}(\mathrm{ppm})$ & $\mathrm{Mg}(\mathrm{ppm})$ & $\mathrm{Mn}(\mathrm{ppm})$ & $\mathrm{Na}(\mathrm{ppm})$ & $\mathrm{Si}(\mathrm{ppm})$ \\
\hline SC4-1 & 1.5 & $327 \pm 1$ & $2.20 \pm 0.01$ & 318 & $1017 \pm 2$ & $0.366 \pm 0.002$ & $7870 \pm 20$ & $14.4 \pm 0.0$ \\
SC4-2 & 4.5 & $355 \pm 1$ & $0.20 \pm 0.01$ & 340 & $1133 \pm 2$ & $0.195 \pm 0.003$ & $8440 \pm 20$ & $20.9 \pm 0.0$ \\
SC4-3 & 7.5 & $350 \pm 2$ & $<0.2$ & 346 & $1192 \pm 2$ & $0.182 \pm 0.004$ & $8600 \pm 30$ & $22.4 \pm 0.1$ \\
SC4-4 & 10.5 & $388 \pm 1$ & $<0.2$ & 374 & $1368 \pm 3$ & $0.275 \pm 0.002$ & $9540 \pm 20$ & $23.0 \pm 0.1$ \\
SC4-5 & 13.5 & $390 \pm 1$ & $<0.2$ & 398 & $1414 \pm 4$ & $0.375 \pm 0.001$ & $9800 \pm 40$ & $21.3 \pm 0.1$ \\
SC4-6 & 16.5 & $410 \pm 2$ & $<0.2$ & 435 & $1493 \pm 3$ & $0.431 \pm 0.001$ & $10400 \pm 200$ & $20.9 \pm 0.0$ \\
SC4-7 & 19.5 & $430 \pm 2$ & $<0.2$ & 474 & $1546 \pm 5$ & $0.271 \pm 0.002$ & $10900 \pm 100$ & $21.3 \pm 0.1$ \\
SC4-8 & 22.5 & $444 \pm 2$ & $0.69 \pm 0.00$ & 487 & $1620 \pm 6$ & $0.173 \pm 0.001$ & $11500 \pm 100$ & $21.4 \pm 0.1$ \\
SC4-9 & 25.5 & $438 \pm 1$ & $<0.2$ & 496 & $1604 \pm 4$ & $<0.1$ & $11400 \pm 100$ & $21.6 \pm 0.1$ \\
SC4-10 & 28.5 & $434 \pm 2$ & $<0.2$ & 560 & $1633 \pm 4$ & $<0.1$ & $11700 \pm 0$ & $21.2 \pm 0.1$ \\
SC4-11 & 31.5 & $436 \pm 3$ & $<0.2$ & 461 & $1639 \pm 3$ & $<0.1$ & $11800 \pm 0$ & $21.7 \pm 0.0$ \\
SC4-12 & 34.5 & $427 \pm 2$ & $<0.2$ & 509 & $1640 \pm 5$ & $<0.1$ & $11800 \pm 100$ & $21.9 \pm 0.1$ \\
\end{tabular}

ICP-MS

\begin{tabular}{|c|c|c|c|c|c|c|c|c|c|c|}
\hline Sample ID & Depth/cm & $\mathrm{Al}(\mathrm{ppb})$ & $\mathrm{Cd}(\mathrm{ppb})$ & $\mathrm{Cr}(\mathrm{ppb})$ & $\mathrm{Cu}(\mathrm{ppb})$ & $\mathrm{Fe}(\mathrm{ppb})$ & Mn (ppb) & $\mathrm{Ni}(\mathrm{ppb})$ & $\mathrm{Pb}(\mathrm{ppb})$ & $\mathrm{Zn}(\mathrm{ppb})$ \\
\hline SC4-1 & 1.5 & $2.4 \pm 0.2$ & $0.19 \pm 0.02$ & $0.53 \pm 0.06$ & $0.52 \pm 0.09$ & $3000 \pm 60$ & $395 \pm 4.0$ & $2.00 \pm 0.24$ & $0.19 \pm 0.02$ & $4.12 \pm 0.70$ \\
\hline SC4-2 & 4.5 & $6.2 \pm 0.1$ & $0.14 \pm 0.02$ & $1.89 \pm 0.23$ & $0.46 \pm 0.08$ & $1400 \pm 70$ & $165 \pm 1.7$ & $1.38 \pm 0.17$ & $0.43 \pm 0.05$ & $4.00 \pm 0.68$ \\
\hline $\mathrm{SC} 4-3$ & 7.5 & $2.6 \pm 0.1$ & $0.80 \pm 0.10$ & $2.35 \pm 0.28$ & $0.35 \pm 0.06$ & $1000 \pm 70$ & $175 \pm 3.5$ & $1.34 \pm 0.16$ & $0.30 \pm 0.04$ & $2.82 \pm 0.48$ \\
\hline SC4-4 & 10.5 & $6.6 \pm 0.1$ & $0.12 \pm 0.01$ & $2.80 \pm 0.34$ & $0.55 \pm 0.09$ & $500 \pm \overline{2} 5$ & $263 \pm 5.3$ & $1.37 \pm 0.16$ & $0.46 \pm 0.06$ & $3.21 \pm 0.55$ \\
\hline SC4-5 & 13.5 & $2.2 \pm 0.1$ & $0.20 \pm 0.02$ & $2.91 \pm 0.35$ & $0.92 \pm 0.16$ & $<1 \overline{10}$ & $462 \pm 9.2$ & $1.25 \pm 0.15$ & $0.38 \pm 0.05$ & $5.61 \pm 0.95$ \\
\hline SC4-6 & 16.5 & $3.8 \pm 0.3$ & $0.08 \pm 0.01$ & $4.19 \pm 0.50$ & $1.00 \pm 0.17$ & $<110$ & $536 \pm 10.7$ & $1.23 \pm 0.15$ & $0.86 \pm 0.10$ & $6.83 \pm 1.16$ \\
\hline SC4-7 & 19.5 & $5.3 \pm 0.2$ & $0.12 \pm 0.01$ & $5.40 \pm 0.65$ & $0.76 \pm 0.13$ & $<110$ & $304 \pm 3.0$ & $1.18 \pm 0.14$ & $1.06 \pm 0.13$ & $7.36 \pm 1.25$ \\
\hline SC4-8 & 22.5 & $3.5 \pm 0.2$ & $0.25 \pm 0.03$ & $5.74 \pm 0.69$ & $2.67 \pm 0.45$ & $<110$ & $188 \pm 1.9$ & $1.19 \pm 0.14$ & $1.05 \pm 0.13$ & $9.45 \pm 1.61$ \\
\hline SC4-9 & 25.5 & $8.2 \pm 0.3$ & $<0 . \overline{06}$ & $6.04 \pm 0.72$ & $1.97 \pm 0.33$ & $<110$ & $52 \pm 0.5$ & $<0 . \overline{2}$ & $0.67 \pm 0.08$ & $6.28 \pm 1.07$ \\
\hline SC4-10 & 28.5 & $38 . \overline{4} \pm 0.8$ & $0.29 \pm 0.03$ & $7.51 \pm 0.90$ & $1.08 \pm 0.18$ & $<110$ & $10 \pm 0.3$ & $1.20 \pm 0.14$ & $1.58 \pm 0.19$ & $5.04 \pm 0.86$ \\
\hline SC4-11 & 31.5 & $4.4 \pm 0.2$ & $0.24 \pm 0.03$ & $9.61 \pm 1.15$ & $0.69 \pm 0.12$ & $<110$ & $2 \pm 0.1$ & $1.00 \pm 0.12$ & $1.65 \pm 0.20$ & $6.88 \pm 1.17$ \\
\hline SC4-12 & 34.5 & $8.3 \pm 0.2$ & $0.63 \pm 0.08$ & $15.38 \pm 1.85$ & $0.94 \pm 0.16$ & $<110$ & $<\overline{1}$ & $0.97 \pm 0.12$ & $4.07 \pm 0.49$ & $8.64 \pm 1.47$ \\
\hline
\end{tabular}

Table 3 Porewater concentrations of total P, total carbon (TC), total inorganic carbon (TIC), and total organic carbon (TOC), total S, Cland $\mathrm{pH}$ from Seaplane Lagoon cores collected on July 10, 1998 (na = not analyzed)

\section{Core SC2}

Sample ID Depth/cm P (ppm) TC (ppm) TIC (ppm) TOC (ppm)

\begin{tabular}{llllll}
\hline SC2-0 & & 0.5 & na & na & na \\
SC2-1 & 1.5 & 1.2 & na & na & na \\
SC2-2 & 4.5 & 2.0 & 80 & na & $<14$ \\
SC2-3 & 7.5 & 1.9 & 95 & 86 & $<14$ \\
SC2-4 & 10.5 & 1.2 & 100 & 84 & 18 \\
SC2-5 & 13.5 & 1.5 & 123 & 119 & 17 \\
SC2-6 & 16.5 & 2.0 & 147 & 161 & $<14$ \\
SC2-7 & 19.5 & 1.7 & 182 & na & na \\
SC2-8 & 22.5 & 2.2 & 230 & 250 & $<14$ \\
SC2-9 & 25.5 & 2.7 & 259 & na & na \\
& & & & & \\
\hline
\end{tabular}

Core SC4

\begin{tabular}{lllll}
\hline Sample ID & Depth/cm & $\mathrm{S}(\mathrm{ppm})$ & $\mathrm{Cl}^{-}(\mathrm{ppt})$ & $\mathrm{pH}$ \\
\hline SC4-1 & 1.5 & 686 & 17.1 & 7.35 \\
SC4-2 & 4.5 & 736 & 17.9 & 7.52 \\
SC4-3 & 7.5 & 759 & 28.7 & 8.05 \\
SC4-4 & 10.5 & 859 & 20.2 & 8.09 \\
SC4-5 & 13.5 & 893 & 21.7 & 7.74 \\
SC4-6 & 16.5 & 949 & 21.6 & 7.83 \\
SC4-7 & 19.5 & 976 & 24.7 & 7.68 \\
SC4-8 & 22.5 & 996 & 25.2 & 7.75 \\
SC4-9 & 25.5 & 952 & 25.5 & 7.56 \\
SC4-10 & 28.5 & 955 & 26.1 & 7.35 \\
SC4-11 & 31.5 & 1036 & 26.0 & 7.76 \\
SC4-12 & 34.5 & 1021 & 27.5 & 7.39 \\
\hline
\end{tabular}

increase at greater depths. In core $\mathrm{SC} 2$, total dissolved total inorganic carbon and total phosphorus concentrations increase with depth.
The dissolved major metal concentrations are close to the equilibrium solubility of common soil minerals (Table 4). Dissolved silica concentrations are close to saturation with respect to $\beta$-cristobalite, a quartz polymorph, but supersaturated with respect to quartz. The dissolved aluminium concentrations are close to saturation with respect to gibbsite, $\left(\mathrm{Al}(\mathrm{OH})_{3}\right)$ and not $7 \AA$ chlorite (micaceous clay) which was identified in the $\mathrm{X}$-ray diffraction analysis of the sediments. The dissolved calcium concentrations are undersaturated with respect to calcite $\left(\mathrm{CaCO}_{3}\right)$ in the surface sediments $(1.5 \mathrm{~cm})$, but supersaturated at greater depths. Apatite $\left(\mathrm{Ca}_{5} \mathrm{OH}\left(\mathrm{PO}_{4}\right)_{3}\right)$ is supersaturated through out the core. In the top $5 \mathrm{~cm}$, dissolved iron concentrations are supersaturated with respect to sulfide phases, and at greater depths, iron concentrations are below detection.

Dissolved trace element concentrations are not exclusively controlled by the solubility of sulfide phases when aqueous complexation by $\mathrm{HS}^{-}$and $\mathrm{S}^{2-}$ is included (Table 4). Of the seven trace elements measured, only cadmium and lead concentrations appear to be limited by the solubility of $\mathrm{CdS}(\mathrm{s})$ and galena $(\mathrm{PbS})$. Zinc and nickel concentrations are supersaturated with respect to sphalerite $(\mathrm{ZnS})$ and millerite $(\mathrm{NiS})$ by $2-4$ orders of magnitude, and manganese and chromium concentrations are undersaturated with respect to alabandnite $(\mathrm{MnS})$ and $\mathrm{CrS}$ (we do not have thermodynamic data for $\mathrm{Cr}_{2} \mathrm{~S}_{3}$ ). The high covellite (CuS) saturation indices (log SI 7-8) may reflect the absence of known formation constants for aqueous copper $\mathrm{HS}^{-}$and $\mathrm{S}^{2-}$ complexes. With the exception of chromium, the stability of trace element $\mathrm{HS}^{-}$and $\mathrm{S}^{2-}$ complexes yields porewaters that are significantly undersaturated with respect to carbonates or hydroxides. Cadmium, copper, lead, nickel, and zinc are all undersaturated with respect to otavite $\left(\mathrm{CdCO}_{3}\right)$ and $\mathrm{Cd}(\mathrm{OH})_{2}$, malachite $\left(\mathrm{Cu}_{2} \mathrm{CO}_{3}(\mathrm{OH})_{2}\right)$, tenorite $(\mathrm{CuO})$, cerussite $\left(\mathrm{PbCO}_{3}\right), \mathrm{NiCO}_{3}$ and $\mathrm{Ni}(\mathrm{OH})_{2}$, rhodochrosite $\left(\mathrm{MnCO}_{3}\right)$ and $\mathrm{Mn}(\mathrm{OH})_{2}$, and smithsonite $\left(\mathrm{ZnCO}_{3}\right)$, and $\beta-\mathrm{Zn}(\mathrm{OH})_{2}$. Dissolved chromium concentrations are 


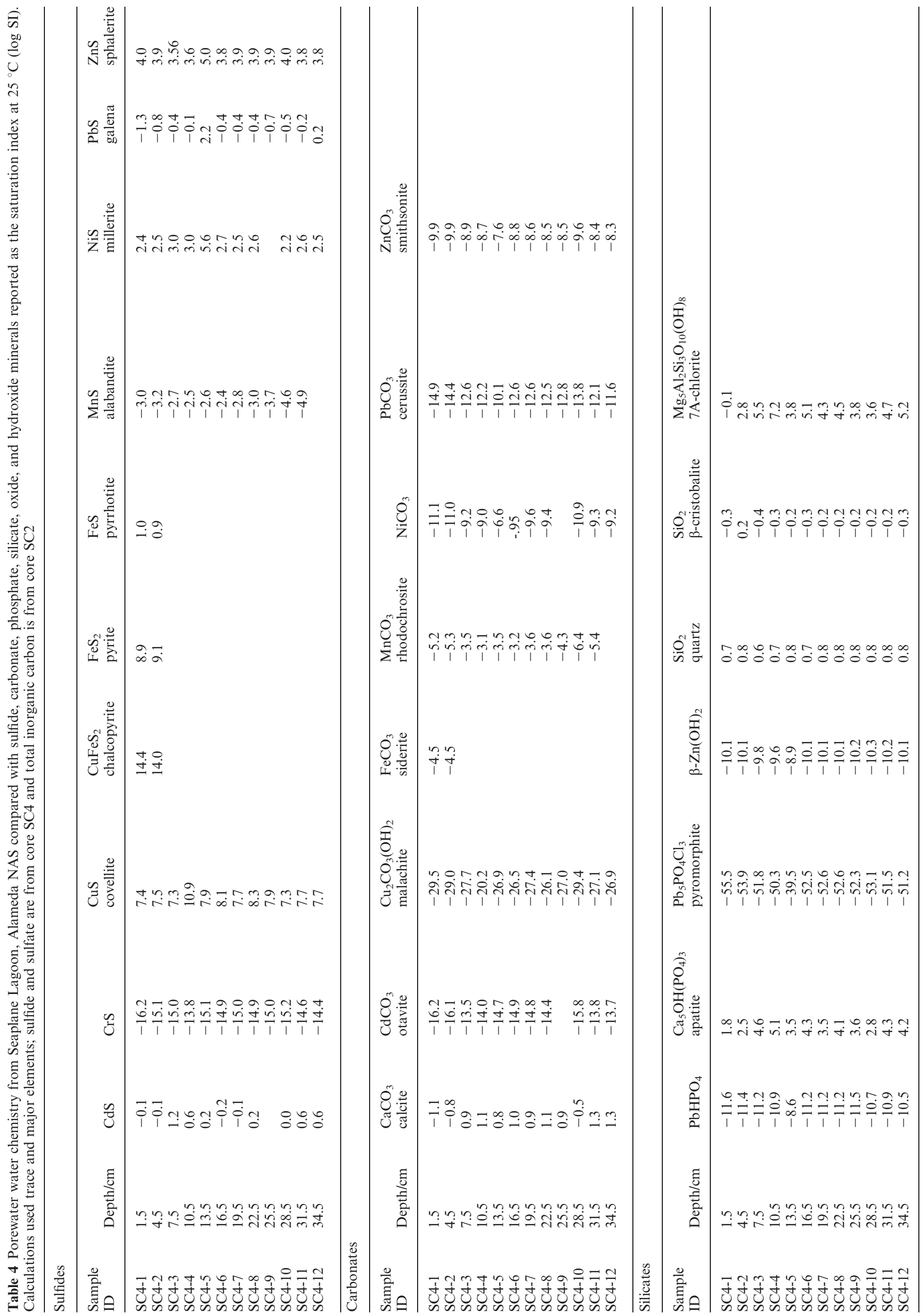


1 to 6 orders-of-magnitude higher than eskolaite $\left(\mathrm{Cr}_{2} \mathrm{O}_{3}\right)$ and magnesiochromite $\left(\mathrm{MgCrO}_{4}\right)$ saturation. Manganese is the only trace metal that may be controlled by phosphate mineral solubility, with concentrations that are slightly undersaturated with respect to $\mathrm{MnHPO}_{4}(\mathrm{~s})$.

\subsection{Depth profiles of the bulk sediment chemistry and mineralogy}

The depth profiles of cadmium, chromium, cobalt, copper, iron, lead, manganese, nickel, sulfur and zinc for the cores are shown in Fig. 3 and tabulated in Table 5. The chemical composition of the sediments with depth is quite uniform in the six cores. In the undisturbed $0.5 \mathrm{~m}$ push cores, cadmium, chromium, copper, lead, mercury, and zinc concentrations increase from low values in the surface sediments to higher values at depths greater than 20 to $30 \mathrm{~cm}$ below the sedimentwater surface. The concentrations range from 10 to $350 \mu \mathrm{g} \mathrm{g}^{-1}$ for cadmium, from 230 to $1150 \mathrm{\mu g} \mathrm{g}^{-1}$ for chromium, from 100 to $240 \mu \mathrm{g} \mathrm{g}^{-1}$ for copper, from 180 to $1400 \mu \mathrm{g} \mathrm{g}^{-1}$ for lead, from 110 to $180 \mu \mathrm{g} \mathrm{g}^{-1}$ for nickel, and from 240 to $630 \mu \mathrm{g} \mathrm{g}^{-1}$ for zinc. Cobalt concentrations are low and vary between 14 and $30 \mu \mathrm{g} \mathrm{g}^{-1}$, with peak concentrations at depths of 20 to $45 \mathrm{~cm}$ as high as $160 \mu \mathrm{g} \mathrm{g}^{-1}$. Manganese concentrations are constant with depth and are about $450 \mu \mathrm{g} \mathrm{g}^{-1}$. Iron concentrations increase from about $4.5 \mathrm{wt} \%$ in the surface sediments to about $5.5 \mathrm{wt}^{\%} \%$ at depths greater than $10 \mathrm{~cm}$. Sulfur concentrations increase from $1 \mathrm{wt} \%$ in the surface sediments to about $2 \mathrm{wt} \%$ at depths of 30 to $40 \mathrm{~cm}$. Gravity cores sampled the sediments to greater depth $(1 \mathrm{~m})$ than the push cores, and show that the trace metals concentrations continue to increase to about $80 \mathrm{~cm}$ (Table 5). At greater depths the concentrations drop to very low levels comparable to the pristine levels in San Francisco Bay. ${ }^{21}$

No trends in sediment mineralogy were observed as a function of depth. The sediments are primarily quartz with about 10 to $15 \mathrm{wt} \%$ phyllosilicate minerals. There is no difference in the bulk mineralogy as a function of depth. Minerals identified in XRD patterns are $80-90 \%$ quartz, and a minimum of $2 \mathrm{wt} \%$ hornblende, mica, chlorite, smectite, illite, and pyrite.

\subsection{Depth profiles of metal bonding from XAS analysis}

Analyses of EXAFS and XANES spectra were used to determine the dominant local coordination environment of individual metals in the sediments. In bulk samples, the absorption signal is an average of all coordination environments of a particular element. Although absorption spectra were collected on samples with porewater present, the XAS signal is dominated by sites associated with solid phases because metal concentrations are roughly three orders-ofmagnitude higher in the solids than in the associated porewater. Ligands in the first coordination shell were identified as either sulfur or oxygen. Quantitative analysis of EXAFS spectra was used to estimate the relative amount of ligation by sulfur (as sulfide) or oxygen atoms, or as a mixture of both atoms. Qualitative comparisons and linear combinations of XANES spectra of reference compounds were used to determine dominant components in the sediment samples for elements for which good quality EXAFS spectra could not be obtained.

3.3.1 Sulfide-associated metals. X-ray absorption spectra for cadmium from two sediment samples show that cadmium is bonded only by first-neighbor sulfur atoms (Fig. 4a). There is no evidence in the EXAFS spectra for coordination by oxygen, which would be evident by a shift to a shorter firstshell distance characteristic of $\mathrm{Cd}-\mathrm{O}$ bond lengths. There is also no evidence for backscattering from atoms beyond the first 

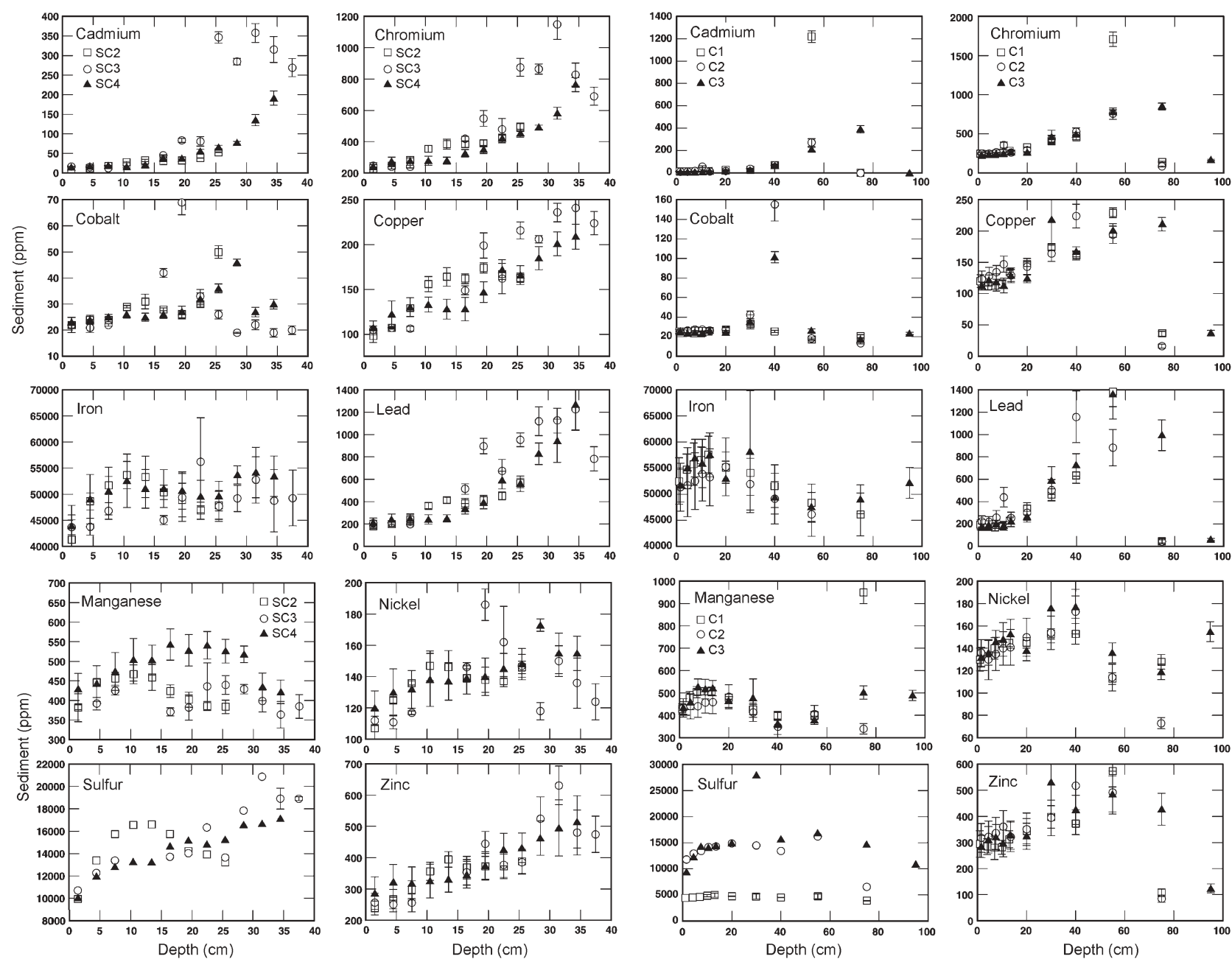

Fig. 3 Chemical composition of Seaplane Lagoon sediments from cores SC2, SC3, SC4 (left hand columns), C1, C2, and C3 (right hand columns).

coordination shell. Sediment spectra are identical to those of two freshly precipitated cadmium sulfide samples, which are the same regardless of whether or not iron was present in the reactant solution. First coordination shell $\mathrm{Cd}-\mathrm{S}$ interatomic distances determined from least-squares fits are similar to those of crystalline CdS (Table 6), consistent with coordination in a sulfide phase (for which $N_{\mathrm{Cd}-\mathrm{S}}=4$ ). The lack of atomic backscattering beyond the sulfur coordination shell for both the natural sediments and the reference laboratory precipitates indicates that the cadmium sulfide phase is highly disordered on a local atomic scale. Although the total cadmium concentrations differ significantly between the sample at $34.5 \mathrm{~cm}$ $\left(192 \mu \mathrm{g} \mathrm{g}^{-1} \mathrm{Cd}\right)$ and at $55.0 \mathrm{~cm}\left(1222 \mu \mathrm{g} \mathrm{g}^{-1} \mathrm{Cd}\right)$, the local coordination determined by EXAFS analysis is identical.

Analyses of zinc EXAFS spectra indicate that zinc is dominantly coordinated in a sulfide phase in the sediments, with a secondary fraction of zinc associated with an oxide component (Fig. 4b). Interatomic distances derived from fits indicate that the sulfide component is locally identical to that of sphalerite $\left(\mathrm{ZnS}\right.$, for which first coordination shell $\left.N_{\mathrm{Zn}-\mathrm{S}}=4\right)$ (Table 6). However, the much lower peak amplitudes in the Fourier transforms of the sediment samples spectra compared to those of crystalline sphalerite show that backscattering from zinc and sulfur atoms beyond the first sulfur shell is weak. This indicates formation of a poorly crystalline sulfide phase and/or small particle size. For the oxide component, zinc EXAFS spectra do not correspond to a single zinc oxide phase. Zinc occurs in oxide and silicate compounds in both octahedral and tetrahedral coordination. First coordination shell leastsquares fits gave average $\mathrm{Zn}-\mathrm{O}$ distances that were variable but consistent with dominantly octahedral coordination of zinc
(Table 6). Analyses of the scattering from second neighbor $\mathrm{Zn}-\mathrm{Me}$ atoms (where $\mathrm{Me}$ is a metal cation) gave interatomic distances indicative of edge sharing of octahedra $\left(R_{\mathrm{Zn}-\mathrm{Me}}=\right.$ 3.06-3.13 $\AA$ ), and of corner sharing of octahedra and/or tetrahedra $\left(R_{\mathrm{Zn}-\mathrm{Me}}=3.21-3.37 \AA\right)$. Because the backscattering functions overlap one another in this range of interatomic distances, the spectra could not be uniquely fit by a single element for each atomic shell. The closer $\mathrm{Zn}-\mathrm{Me}$ shell could be fit with a combination of iron (or similar $Z$ transition metal), magnesium, or aluminium. The more distant $\mathrm{Zn}-\mathrm{Me}$ shell could be fit with iron, aluminium, or silicon. These observations suggest zinc substitution in one or more silicate or oxide phases. Given that phyllosilicate minerals comprise about 10 $15 \mathrm{wt} \%$ of the bulk sample, it is likely that some zinc is present in these minerals. Substitution of zinc into the octahedral sites of clay minerals or micas is consistent with the interatomic distances determined for the oxide component. Substitution of small amounts of zinc into other oxide phases such as magnetite cannot be determined from these data.

The relative atomic proportions of zinc sulfide and oxide components in the sediments were estimated from fits to Fourier-filtered first coordination shell EXAFS spectra. Zinc was assumed to be tetrahedrally coordinated by sulfur in the sulfide component and octahedrally coordinated by oxygen in the oxide component. In fits to the total EXAFS spectra, interatomic distances and coordination numbers $(N)$ for zinc and sulfur shells were fixed on crystallographic values for sphalerite (Table 6), with $N$ scaled to the proportion of sulfide component determined in the first coordination shell fit. Using this approach, there is little change in the relative proportions of sulfide and oxide components as a function of depth in core 


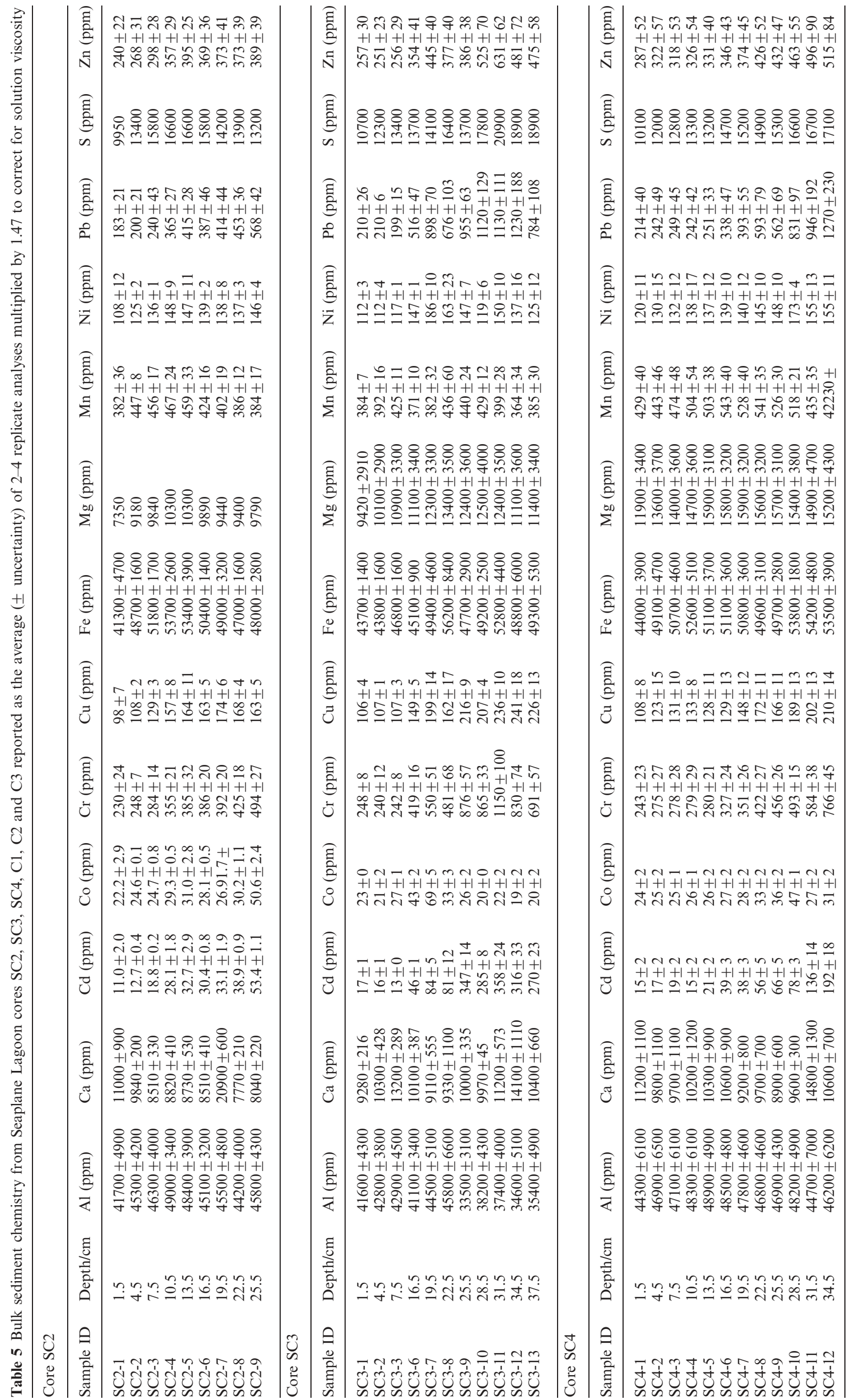



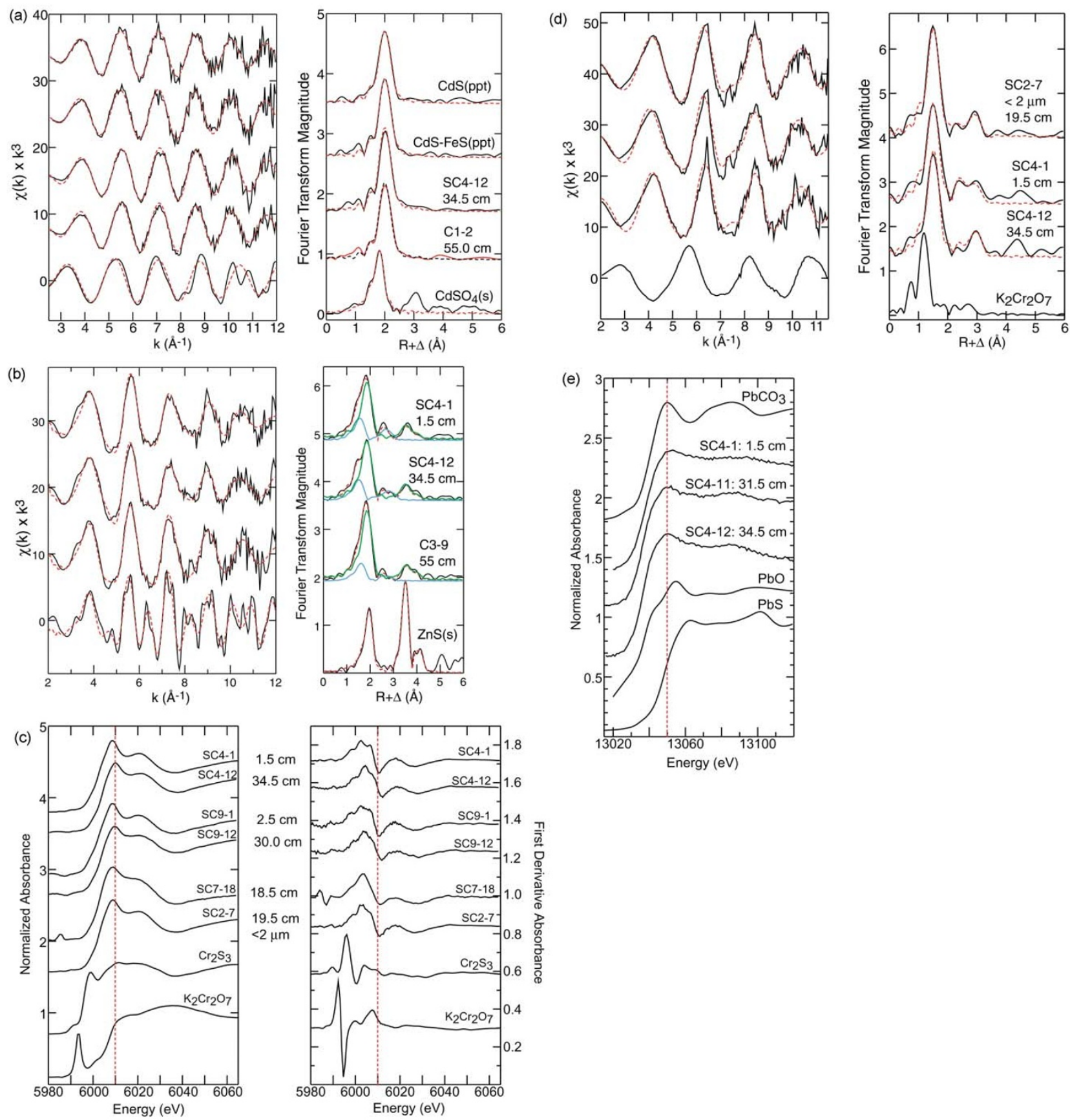

Fig. 4 (a) Normalized EXAFS and corresponding radial structure functions (uncorrected for phase shift of backscattering atoms) for cadmium in two NAS Alameda sediment samples from core SC4-12 $(34.5 \mathrm{~cm})$ and core $\mathrm{C} 1-2(5.5 \mathrm{~cm})$ compared to reference precipitates, cadmium sulfide $(\mathrm{CdS}(\mathrm{ppc}))$ and a mixture of cadmium and iron sulfide $(\mathrm{CdS}-\mathrm{FeS})$ precipitated from solution immediately before data collection, and crystalline cadmium sulfate $\left(\mathrm{CdSO}_{4}(\mathrm{~s})\right)$. Dashed red line is the non-linear least-squares best fit. (b) Normalized EXAFS and corresponding radial structure functions (uncorrected for phase shift of backscattering atoms) for zinc in sediment samples from core SC4 (at $1.5 \mathrm{and} 34.5 \mathrm{~cm}$ ) and core C3-9 (55 cm) compared to a reference spectrum of crystalline sphalerite $(\mathrm{ZnS}(\mathrm{s}))$. Dashed red line is the non-linear least-squares best fit; green line is the fit component corresponding to sphalerite; blue line is the fit for a zinc-oxygen component that probably represents zinc substitution in detrital phyllosilicate or oxide minerals. (c) Normalized XANES spectra and corresponding first-derivative spectra for chromium in samples from cores SC4 (at 1.5 and $34.5 \mathrm{~cm}$ ), SC9 (at 2.5 and $30 \mathrm{~cm}$ ) and SC7 (at $18.5 \mathrm{~cm}$ ) compared with reference spectra for crystalline chromium sulfide and potassium chromate compounds. (d) Normalized EXAFS and corresponding radial structure functions (uncorrected for phase shift of backscattering atoms) for chromium in sediment samples SC2-7, SC4-1, and SC4-12 compared to reference crystalline potassium chromate. Dashed red line is the nonlinear least-squares best fit. Oxidation of $\mathrm{Cr}(\mathrm{III})$ to $\mathrm{Cr}(\mathrm{VI})$ results in a significant shift of the first-shell oxygen peak to shorter interatomic distance. (e) Normalized XANES spectra for lead in samples from core SC4 (at 1.5, 31.5, and $34.5 \mathrm{~cm}$ ) compared with reference spectra for crystalline lead sulfide, oxide, and carbonate compounds.

SC4. The oxide component comprises $22-25 \%$ of the zinc atomic component even though total zinc concentration increases from $287 \mu \mathrm{g} \mathrm{g}^{-1}$ at $2.5 \mathrm{~cm}$ to $515 \mu \mathrm{g} \mathrm{g}^{-1}$ at $34.5 \mathrm{~cm}$. In a different core (C3), a sample from $55 \mathrm{~cm}$ depth shows a higher relative proportion of sulfide component, about $90 \%$, although the total zinc concentration $\left(486 \mu \mathrm{g} \mathrm{g}^{-1}\right)$ is similar to that of core SC4 at $34.5 \mathrm{~cm}\left(515 \mu \mathrm{g} \mathrm{g}^{-1}\right)$.
3.3.2 Oxide-associated metals. Both chromium and lead are associated with oxide phases in the sediments and there is no evidence for association with sulfide minerals. Analyses of XANES (Fig. 4c) and EXAFS (Fig. 4d) spectra for chromium show no evidence for the presence of sulfur backscatterers and indicate $\mathrm{Cr}(\mathrm{III})$ only. The presence of $\mathrm{Cr}(\mathrm{VI})$ would be readily apparent by a distinctive pre-edge feature in the XANES 
Table 6 EXAFS analyses

Cadmium EXAFS analysis

\begin{tabular}{|c|c|c|c|c|c|}
\hline Core & Atom & $R / \AA ̊$ & $N$ & $\sigma^{2} / \AA^{2}$ & $\Delta E_{0} / \mathrm{eV}$ \\
\hline \multicolumn{6}{|l|}{ Sediments } \\
\hline SC4-12 & $\mathrm{Cd}-\mathrm{S}^{a}$ & $2.50^{e}$ & 4.0 & $0.0044^{e}$ & $-1.0^{e}$ \\
\hline \multicolumn{6}{|l|}{$34.5 \mathrm{~cm}$} \\
\hline \multicolumn{6}{|l|}{192 ppm } \\
\hline $\mathrm{C} 1-2$ & $\mathrm{Cd}-\mathrm{S}^{a}$ & $2.51^{e}$ & 4.0 & $0.0051^{e}$ & $-1.4^{e}$ \\
\hline \multicolumn{6}{|l|}{$55.0 \mathrm{~cm}$} \\
\hline \multicolumn{6}{|l|}{1222 ppm } \\
\hline SC4-11 & $\mathrm{Cd}-\mathrm{S}^{b}$ & 2.51 & $1.9^{e}$ & 0.0050 & $-4.1^{e}$ \\
\hline $31.5 \mathrm{~cm}$ & $\mathrm{Cd}-\mathrm{O}^{b}$ & $2.31^{e}$ & $3.2^{e}$ & $0.0120^{e}$ & \\
\hline \multicolumn{6}{|l|}{ Leached } \\
\hline \multicolumn{6}{|c|}{ Reference precipitates $^{c}$} \\
\hline $\mathrm{Cd}_{1.0} \mathrm{~S}$ & $\mathrm{Cd}-\mathrm{S}$ & $2.51^{e}$ & 4.0 & $0.0056^{e}$ & $-1.7^{e}$ \\
\hline $\mathrm{Cd}_{0.25} \mathrm{~S}$ & $\mathrm{Cd}-\mathrm{S}$ & $2.51^{e}$ & 4.0 & $0.0048^{e}$ & $-2.6^{e}$ \\
\hline \multicolumn{6}{|c|}{ Reference compound: greenockite $(\mathrm{CdS})^{d}$} \\
\hline & $\mathrm{Cd}-\mathrm{S}$ & 2.52 & 1 & & \\
\hline & $\mathrm{Cd}-\mathrm{S}$ & 2.53 & 3 & & \\
\hline & $\mathrm{Cd}-\mathrm{Cd}$ & 4.12 & 6 & & \\
\hline & $\mathrm{Cd}-\mathrm{Cd}$ & 4.13 & 6 & & \\
\hline
\end{tabular}

Scale factor $\left(S_{0}{ }^{2}\right)=1.5{ }^{a}$ First-shell $\mathrm{Cd}-\mathrm{S}$ coordination fixed at 4; $R$ and $\sigma^{2}$ were varied. ${ }^{b}$ For the sulfide component, $R$ and $\sigma^{2}$ were fixed on the average of values determined from fits to reference precipitates; $N$ was varied. If $N_{\mathrm{Cd}-\mathrm{S}}=4$ and $N_{\mathrm{Cd}-\mathrm{O}}=6$ are assumed, then the sulfide component is $47 \%$ and the oxide component is $53 \%$ of the total absorption spectrum. ${ }^{c}$ Cadmium sulfide was precipitated by adapting an FeS method. ${ }^{10}$ XAS spectra collected on wet samples immediately after precipitation. ${ }^{d}$ Crystallographic values for greenockite from ref. 58. ${ }^{e}$ Parameter varied in least-squares fits.

Zinc EXAFS analysis

\begin{tabular}{|c|c|c|c|c|c|c|}
\hline Core & Rel. \% & Atom & $R / \AA$ & $N$ & $\sigma^{2} / \AA^{2}$ & $\Delta E_{0} / \mathrm{eV}$ \\
\hline \multicolumn{7}{|c|}{ Sulfide component $t^{f}$} \\
\hline SC4-1 & 75 & $\mathrm{Zn}-\mathrm{S}$ & 2.33 & $3.0^{l}$ & 0.0065 & $-5.2^{l}$ \\
\hline $2.5 \mathrm{~cm}$ & & $\mathrm{Zn}-\mathrm{Zn}$ & 3.83 & 8.9 & $0.0231^{l}$ & \\
\hline $287 \mathrm{ppm}$ & & $\mathrm{Zn}-\mathrm{S}$ & 4.49 & 8.9 & $0.0267^{l}$ & \\
\hline SC4-12 & 78 & $\mathrm{Zn}-\mathrm{S}$ & 2.33 & $3.1^{l}$ & 0.0065 & $-6.3^{l}$ \\
\hline $34.5 \mathrm{~cm}$ & & $\mathrm{Zn}-\mathrm{Zn}$ & 3.83 & 9.3 & $0.0221^{l}$ & \\
\hline $515 \mathrm{ppm}$ & & $\mathrm{Zn}-\mathrm{S}$ & 4.49 & 9.3 & $0.0297^{l}$ & \\
\hline C3-9 & 90 & $\mathrm{Zn}-\mathrm{S}$ & 2.33 & $3.6^{l}$ & 0.0065 & $-5.2^{l}$ \\
\hline $55.0 \mathrm{~cm}$ & & $\mathrm{Zn}-\mathrm{Zn}$ & 3.83 & 10.8 & $0.0259^{l}$ & \\
\hline $486 \mathrm{ppm}$ & & $\mathrm{Zn}-\mathrm{S}$ & 4.49 & 10.8 & $0.0257^{l}$ & \\
\hline SC4-11 & 25 & $\mathrm{Zn}-\mathrm{S}$ & 2.33 & $0.9^{l}$ & 0.0065 & $-5.9^{l}$ \\
\hline $31.5 \mathrm{~cm}$ & & $\mathrm{Zn}-\mathrm{Zn}$ & 3.82 & 2.6 & $0.0225^{l}$ & \\
\hline Leached & & $\mathrm{Zn}-\mathrm{S}$ & 4.49 & 2.6 & $0.0139^{l}$ & \\
\hline \multicolumn{7}{|c|}{ Oxide component ${ }^{g}$} \\
\hline SC4-1 & 25 & $\mathrm{Zn}-\mathrm{O}$ & $2.04^{l}$ & $1.7^{l}$ & 0.0065 & $-5.2^{l}$ \\
\hline $2.5 \mathrm{~cm}$ & & $\mathrm{Zn}-\mathrm{Me}^{h}$ & $3.13^{l}$ & $1.0^{l}$ & 0.0080 & \\
\hline $287 \mathrm{ppm}$ & & $\mathrm{Zn}-\mathrm{Me}^{i}$ & $3.13^{l}$ & $0.8^{l}$ & 0.0100 & \\
\hline SC4-12 & 22 & $\mathrm{Zn}-\mathrm{O}$ & $1.99^{l}$ & $1.4^{l}$ & 0.0065 & $-6.3^{l}$ \\
\hline $34.5 \mathrm{~cm}$ & & $\mathrm{Zn}-\mathrm{Me}^{h}$ & $3.06^{l}$ & $0.9^{l}$ & 0.0080 & \\
\hline $515 \mathrm{ppm}$ & & $\mathrm{Zn}-\mathrm{Me}^{i}$ & $3.13^{l}$ & $0.8^{l}$ & 0.0080 & \\
\hline & & $\mathrm{Zn}-\mathrm{Me}^{j}$ & $3.21^{l}$ & $1.7^{l}$ & 0.0080 & \\
\hline C3-9 & 10 & $\mathrm{Zn}-\mathrm{O}$ & $2.09^{l}$ & $1.4^{l}$ & 0.0065 & $-5.2^{l}$ \\
\hline $55.0 \mathrm{~cm}$ & & $\mathrm{Zn}-\mathrm{Me}^{f}$ & $3.10^{l}$ & $0.4^{l}$ & 0.0080 & \\
\hline 486 ppm & & & & & & \\
\hline SC4-11 & 75 & $\mathrm{Zn}-\mathrm{O}$ & $2.02^{l}$ & $3.2^{l}$ & 0.0065 & $-5.9^{l}$ \\
\hline $31.5 \mathrm{~cm}$ & & $\mathrm{Zn}-\mathrm{Me}^{h}$ & $3.13^{l}$ & $1.3^{l}$ & 0.0080 & \\
\hline Leached & & $\mathrm{Zn}-\mathrm{Me}^{j}$ & $3.39^{l}$ & $0.6^{l}$ & 0.0080 & \\
\hline \multicolumn{7}{|c|}{ Reference compound: sphalerite $(\mathrm{ZnS})^{k}$} \\
\hline & & $\mathrm{Zn}-\mathrm{S}$ & 2.33 & 4 & & \\
\hline & & $\mathrm{Zn}-\mathrm{Zn}$ & 3.83 & 12 & & \\
\hline & & $\mathrm{Zn}-\mathrm{S}$ & 4.49 & 12 & & \\
\hline
\end{tabular}

Scale factor $\left(S_{0}{ }^{2}\right)=1.0 .{ }^{f}$ Sulfide component: Interatomic distances $(R)$ for $\mathrm{Zn}-\mathrm{S}$ and $\mathrm{Zn}-\mathrm{Zn}$ fixed on crystallographic values in sphalerite; first-shell $\sigma^{2}$ for $\mathrm{Zn}-\mathrm{S}$ was fixed on an empirical value determined from fits to sulfide reference compounds. For higher $\mathrm{Zn}-\mathrm{Zn}$ and $\mathrm{Zn}-\mathrm{S}$
Table 6 EXAFS analyses (continued)

shells, $N$ was fixed on the value calculated from the proportion of sphalerite component determined in fits to filtered first-shell spectra and $\sigma^{2}$ was varied. ${ }^{g}$ Oxide component: Values for $\sigma^{2}$ were fixed for all shells based on empirical fits to reference compounds; $R$ and $N$ were varied. ${ }^{h}$ Backscatterer is $\mathrm{Fe}$ or similar transition metal cation; edge-sharing octahedra. ${ }^{i}$ Backscatterer is $\mathrm{Mg}$ or $\mathrm{Al}$; edge-sharing octahedra. ${ }^{j}$ Backscatterer is $\mathrm{Fe}$ or $\mathrm{Si}$; corner-sharing octahedra or tetrahedra. ${ }^{k}$ Crystallographic values for sphalerite from ref. 28 . ${ }^{l}$ Parameter varied in least-squares fit.

Chromium EXAFS analysis

\begin{tabular}{llllll}
\hline Core & Atom & $R / \AA$ & $N$ & $\sigma^{2} / \AA^{2}$ & $\Delta E_{0} / \mathrm{eV}$ \\
\hline Oxide component $^{m}$ & & & & & \\
$\mathrm{SC}^{2}-7$ & $\mathrm{Cr}-\mathrm{O}$ & $1.97^{s}$ & 6.0 & $0.0035^{s}$ & $-8.5^{s}$ \\
$19.5 \mathrm{~cm}$ & $\mathrm{Cr}-\mathrm{Me}^{n}$ & $3.01^{s}$ & $1.9^{s}$ & 0.0100 & \\
$<2 \mu \mathrm{m}$ & $\mathrm{Cr}-\mathrm{Me}{ }^{o}$ & $3.00^{s}$ & $1.7^{s}$ & 0.0100 & \\
$392 \mathrm{ppm}$ & $\mathrm{Cr}-\mathrm{Fe}$ & $3.42^{s}$ & $1.8^{s}$ & 0.0080 & \\
$\mathrm{SC}-1$ & $\mathrm{Cr}-\mathrm{O}$ & $1.98^{s}$ & 6.0 & $0.0041^{s}$ & $-8.9^{s}$ \\
$1.5 \mathrm{~cm}$ & $\mathrm{Cr}-\mathrm{Me}$ & $2.97^{s}$ & $1.6^{s}$ & 0.0080 & \\
$243 \mathrm{ppm}$ & $\mathrm{Cr}-\mathrm{Fe}$ & $3.44^{s}$ & $1.9^{s}$ & 0.0080 & \\
$\mathrm{SC}-12$ & $\mathrm{Cr}-\mathrm{O}$ & $1.97^{s}$ & 6.0 & $0.0041^{s}$ & $-6.0^{s}$ \\
$34.5 \mathrm{~cm}$ & $\mathrm{Cr}-\mathrm{Me}$ & $3.02^{s}$ & $1.1^{s}$ & 0.0100 & \\
$766 \mathrm{ppm}$ & $\mathrm{Cr}-\mathrm{Fe}$ & $3.44^{s}$ & $2.2^{s}$ & 0.0080 & \\
$\mathrm{SC} 4-11$ & $\mathrm{Cr}-\mathrm{O}$ & $1.98^{s}$ & 6.0 & $0.0037^{s}$ & $-8.8^{s}$ \\
$31.5 \mathrm{~cm}$ & $\mathrm{Cr}-\mathrm{O}^{p}$ & $3.00^{s}$ & $1.8^{s}$ & 0.0100 & \\
Leached & $\mathrm{Cr}-\mathrm{Fe}$ & $3.42^{s}$ & $1.2^{s}$ & 0.0080 &
\end{tabular}

Reference compounds

$\begin{array}{llll}\mathrm{Cr}_{2} \mathrm{~S}_{3}{ }^{q} & \mathrm{Cr}-\mathrm{S} & 2.42 & 6 \\ & \mathrm{Cr}-\mathrm{Cr} & 2.79 & 2 \\ \mathrm{~K}_{2} \mathrm{Cr}_{2} \mathrm{O}_{7}{ }^{r} & \mathrm{Cr}-\mathrm{S} & 4.20 & 6 \\ & \mathrm{Cr}-\mathrm{O} & 1.52,1.54, & 4 \\ & & 1.73,1.85 & \\ & \mathrm{Cr}-\mathrm{Cr} & 3.13 & 1 \\ & \mathrm{Cr}-\mathrm{K} & 3.26 & 1\end{array}$

Scale factor $\left(S_{0}{ }^{2}\right)=0.90 .{ }^{m}$ Oxide component: First-shell $\mathrm{Cr}-\mathrm{O}$ coordination fixed at $6 ; \sigma^{2}$ was varied. For higher shells, values for $\sigma^{2}$ were fixed based on empirical fits to reference compounds; $R$ and $N$ were varied. ${ }^{n}$ Backscatterer is $\mathrm{Mg}$ or $\mathrm{Al}$; edge-sharing octahedra. ${ }^{o}$ Backscatterer is $\mathrm{Fe}$ or similar transition metal cation; edge-sharing octahedra. ${ }^{p}$ Fit with single shell of Fe atoms; probably a disordered shell of $\mathrm{Al}, \mathrm{Mg}$, and $\mathrm{Fe}$ atoms. ${ }^{q}$ Crystallographic values from ref. 59. ${ }^{r}$ Crystallographic values from ref. 60 . ${ }^{s}$ Parameter varied in leastsquares fits.

\begin{tabular}{|c|c|c|c|c|c|c|}
\hline \multicolumn{7}{|c|}{ Iron EXAFS analysis } \\
\hline Core & Rel. \% & Atom & $R / \AA ̊$ & $N^{w}$ & $\sigma^{2} / \AA^{2}$ & $\Delta E_{0} / \mathrm{eV}$ \\
\hline \multicolumn{7}{|c|}{ Pyrite component ${ }^{t}$} \\
\hline SC4-1 & 35.6 & $\mathrm{Fe}-\mathrm{S}$ & 2.25 & 0.80 & 0.0011 & $-7.2^{w}$ \\
\hline \multirow[t]{2}{*}{$2.5 \mathrm{~cm}$} & & $\mathrm{Fe}-\mathrm{S}$ & 3.44 & 0.80 & 0.0066 & \\
\hline & & $\mathrm{Fe}-\mathrm{Fe}$ & 3.82 & 1.60 & 0.0066 & \\
\hline SC4-12 & 38.5 & $\mathrm{Fe}-\mathrm{S}$ & 2.25 & 0.92 & 0.0011 & $-6.7^{w}$ \\
\hline \multirow[t]{2}{*}{$34.5 \mathrm{~cm}$} & & $\mathrm{Fe}-\mathrm{S}$ & 3.44 & 0.92 & 0.0066 & \\
\hline & & $\mathrm{Fe}-\mathrm{Fe}$ & 3.82 & 1.84 & 0.0066 & \\
\hline SC4-11 & 21.4 & $\mathrm{Fe}-\mathrm{S}$ & 2.25 & 0.66 & 0.0011 & $-8.3^{w}$ \\
\hline $31.5 \mathrm{~cm}$ & & $\mathrm{Fe}-\mathrm{S}$ & 3.44 & 0.66 & 0.0066 & \\
\hline Leached & & $\mathrm{Fe}-\mathrm{Fe}$ & 3.82 & 1.32 & 0.0066 & \\
\hline \multicolumn{7}{|c|}{ Oxide component ${ }^{u}$} \\
\hline SC4-1 & 64.4 & $\mathrm{Fe}-\mathrm{O}$ & $2.00^{w}$ & 2.64 & 0.0048 & $-3.4^{w}$ \\
\hline \multirow[t]{3}{*}{$2.5 \mathrm{~cm}$} & & $\mathrm{Fe}-\mathrm{Fe}$ & $3.10^{w}$ & 0.53 & 0.0050 & \\
\hline & & $\mathrm{Fe}-\mathrm{Si}$ & 3.26 & 1.43 & 0.0057 & \\
\hline & & $\mathrm{Fe}-\mathrm{Fe}$ & $3.39^{w}$ & 0.29 & 0.0057 & \\
\hline SC4-12 & 61.5 & $\mathrm{Fe}-\mathrm{O}$ & $2.00^{w}$ & 2.79 & 0.0048 & $-3.2^{w}$ \\
\hline \multirow[t]{3}{*}{$34.5 \mathrm{~cm}$} & & $\mathrm{Fe}-\mathrm{Fe}$ & $3.09^{w}$ & 0.62 & 0.0050 & \\
\hline & & $\mathrm{Fe}-\mathrm{Si}$ & 3.26 & 1.15 & 0.0057 & \\
\hline & & $\mathrm{Fe}-\mathrm{Fe}$ & $3.43^{w}$ & 0.41 & 0.0057 & \\
\hline SC4-11 & 78.6 & $\mathrm{Fe}-\mathrm{O}$ & $2.00^{w}$ & 3.12 & 0.0048 & $-0.5^{w}$ \\
\hline $31.5 \mathrm{~cm}$ & & $\mathrm{Fe}-\mathrm{Fe}$ & $3.09^{w}$ & 0.92 & 0.0050 & \\
\hline \multirow[t]{2}{*}{ Leached } & & $\mathrm{Fe}-\mathrm{Si}$ & 3.26 & 0.82 & 0.0057 & \\
\hline & & $\mathrm{Fe}-\mathrm{Fe}$ & $3.39^{w}$ & 0.41 & 0.0057 & \\
\hline
\end{tabular}


Table 6 EXAFS analyses (continued)

Reference compound: pyrite $\left(\mathrm{FeS}_{2}\right)^{v}$

$\begin{array}{ll}\mathrm{Fe}-\mathrm{S} & 2.25 \\ \mathrm{Fe}-\mathrm{S} & 3.44 \\ \mathrm{Fe}-\mathrm{Fe} & 3.82\end{array}$

$\mathrm{Fe}-\mathrm{Fe}$

3.82

12

${ }^{t}$ Pyrite component: Interatomic distances $(R)$ were fixed on crystallographic values from pyrite and $\sigma^{2}$ was fixed on values determined from fits to reference sulfide compounds. $N$ for each shell was floated as a linked variable in proportions based on the known coordination in pyrite. Relative percent (Rel. \%) for pyrite or oxide components is calculated from the integrated fit areas of all atomic shells comprising each component (normalized to $100 \%$ ). " Values for $\sigma^{2}$ were fixed for all shells based on empirical fits to reference compounds of similar composition and structure; $R$ and $N$ were varied, except for the Fe-Si shell, which will co-vary with Fe shells if floated independently. This shell was fixed on a typical crystallographic distance for $\mathrm{Fe}-\mathrm{Si}$ in phyllosilicates. ${ }^{v}$ Crystallographic values from ref. 61. ${ }^{w}$ Parameter varied in least-squares fit.

spectrum and by much shorter $\mathrm{Cr}-\mathrm{O}$ distances than obtained in first coordination shell fits to the EXAFS spectra (Table 6). Comparison of normalized and first-derivative XANES spectra for shallow and deep sediments from two cores (SC4 and SC9) are very similar, with slight differences in spectral shape above the energy of maximum absorption revealed in firstderivative spectra (Fig. 4c). XANES spectra of two samples from intermediate depths (SC7-18 and SC2-7) are very similar to the chromium spectra of shallow cores.

Likewise, EXAFS spectra for three sediment samples are generally very similar regardless of total chromium concentration which increases with depth in core SC4 from $245 \mu \mathrm{g} \mathrm{g}^{-1}$ at $1.5 \mathrm{~cm}$ to $766 \mu \mathrm{g} \mathrm{g}^{-1}$ at $34.5 \mathrm{~cm}$. All spectra have identical first-shell coordination and slight differences in backscattering amplitudes for more distant atomic shells (Fig. 4d and Table 6). Interatomic distances obtained from EXAFS fits do not correspond to a single identifiable chromium oxide phase. First coordination shell $\mathrm{Cr}-\mathrm{O}$ distances are typical of octahedral coordination of $\mathrm{Cr}(\mathrm{III})$ by oxygen in oxide and silicate compounds. Distances obtained from fitting of higher shells are consistent with edge-sharing of metal octahedra and cornersharing of metal octahedra and/or tetrahedra. Differences in the amplitude of backscattering from atoms at 2.97-3.02 appear to be related to cancellation effects among atoms such as iron (or similar $Z$ elements), magnesium, and aluminium at slightly different $\mathrm{Cr}-\mathrm{Me}$ interatomic distances. Backscattering from atoms at 3.42-3.44 $\AA$ is more consistent and best fit with iron. These structural results are consistent with chromium substitution in phyllosilicates, association with spinel phases such as chromite or magnetite, and/or inner-sphere adsorption on oxides or silicates. As discussed below, chromium in the sediments originates from both contaminant and detrital sources, with the contaminant fraction dominant in deeper sediments. The spectral results, however, do not indicate major changes in chromium bonding with depth.

Comparison of XANES spectra for lead in the sediments and in reference compounds indicates that lead is bonded by oxygen. Coordination of lead by sulfur would result in a shift of maximum absorption at the $\mathrm{Pb}_{\mathrm{III}}$ edge to significantly lower energy (Fig. 4e). The energy of maximum absorption is consistent with lead coordination in either oxide, phosphate, or carbonate phases. There are no changes in the XANES spectra of samples from core SC4 even though the total lead concentration increases significantly from $214 \mu \mathrm{g} \mathrm{g}^{-1}$ at $1.5 \mathrm{~cm}$ to $1269 \mu \mathrm{g} \mathrm{g}^{-1}$ at $34.5 \mathrm{~cm}$. Previous analysis of first-neighbor atomic scattering in one lead EXAFS spectrum (SC9-12, $30 \mathrm{~cm}$ depth) indicated the presence of oxygen atoms only. ${ }^{22}$ Quantitative analyses of two lead EXAFS spectra from core SC4 were precluded by poor data quality, but there was no evidence for backscattering from sulfur atoms. Lead exhibits high static disorder in its local oxygen coordination in a (a)
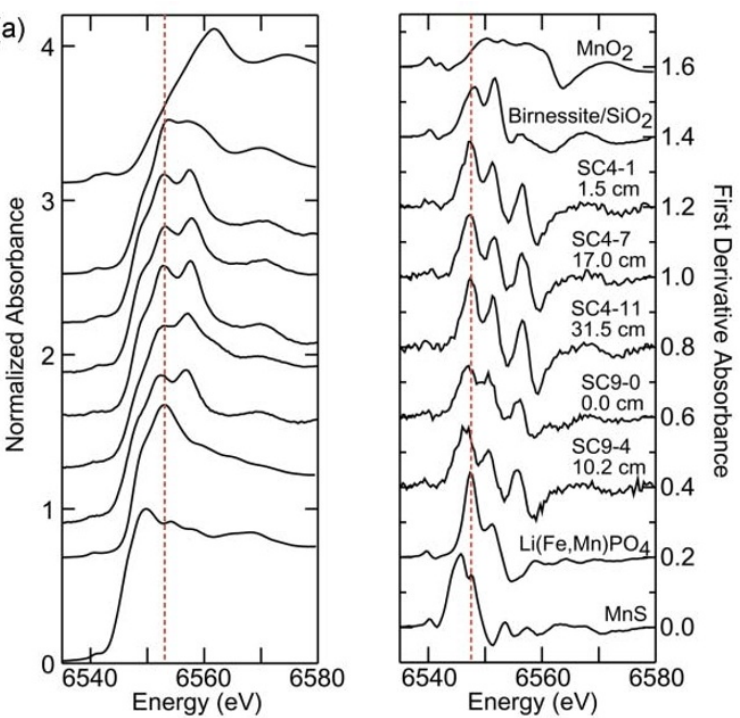

(b)
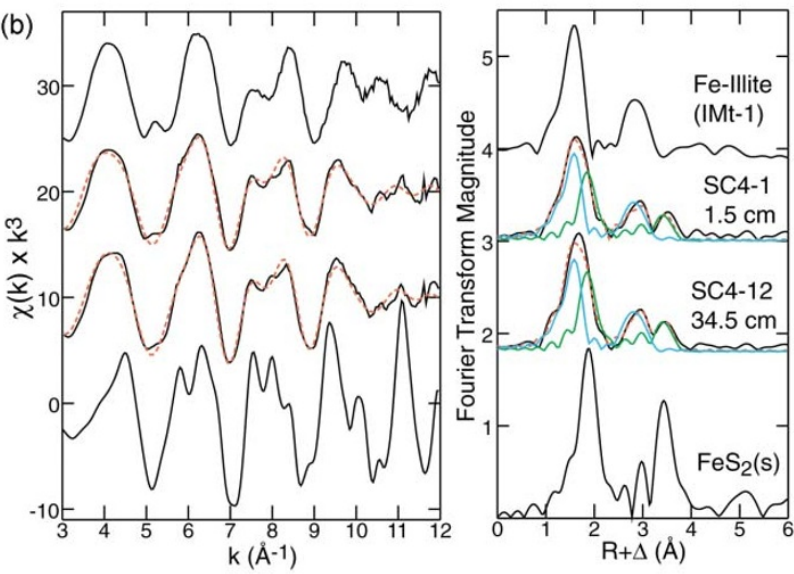

Fig. 5 (a) Normalized XANES spectra and corresponding firstderivative spectra for manganese in samples from cores SC4 (at 1.5, 17.0, and $31.5 \mathrm{~cm}$ ) and SC9 (at 0.0 and $10.2 \mathrm{~cm}$ ) compared with reference spectra for synthetic manganese(Iv) oxide $\left(\mathrm{MnO}_{2}\right.$, pyrolusite), birnessite (layered Mn(III,IV) oxide) precipitated on quartz (birnessite/ $\left.\mathrm{SiO}_{2}\right)$, a natural $\mathrm{Mn}$-phosphate $\left(\mathrm{Li}(\mathrm{Fe}, \mathrm{Mn}) \mathrm{PO}_{4}\right.$, ferrisicklerite), and $\mathrm{Mn}$ (II) sulfide (MnS). (b) Normalized EXAFS and corresponding radial structure functions (uncorrected for phase shift of backscattering atoms) for iron in sediment samples from core SC4 (at 1.4 and $34.5 \mathrm{~cm}$ ) compared to reference spectra of crystalline pyrite $\left(\mathrm{FeS}_{2}(\mathrm{~s})\right)$ and of iron substituted in reference illite IMt-1 (Clay Minerals Source Repository). Dashed red line is the non-linear least-squares best fit; green line is the fit component corresponding to pyrite; blue line is the fit for an ironoxygen component that probably represents iron substitution in phyllosilicate or oxide minerals

number of lead oxide, (oxy)hydroxide, phosphate, and carbonate compounds, and thus, first coordination shell distances are not diagnostic of a particular phase. ${ }^{16,23,24}$ Evidence from the XANES and EXAFS spectra are consistent with lead coordination in either carbonate, phosphate, or (oxy)hydroxide phases, or as an oxygen-ligated sorbed complex.

3.3.3 Manganese and iron. Manganese concentrations in the sediments vary between $350-550 \mu \mathrm{g} \mathrm{g}^{-1}$ and do not generally increase with depth, as do the contaminant metals. Comparison of the manganese XANES spectra as a function of depth in core SC4 indicates no significant changes among samples between 1.5 and $31.5 \mathrm{~cm}$ (Fig. 5a). Examination of firstderivative XANES spectra shows only slight variations in the energy positions of major inflection points among the sediment samples. The sediment XANES spectra could not be entirely fit with a single reference compound or by linear combinations of two or three manganese reference compounds, including combinations of carbonate, phosphate, sulfate, sulfide, and 
oxide minerals. This suggests that manganese is substituting in other minerals or forming solid solutions rather than forming pure manganese compounds. Absorption edge features from $\sim 6548-6555 \mathrm{eV}$ are similar to a natural speciman of ferrisicklerite $\left(\mathrm{Li}\left[\mathrm{Fe}^{3+}, \mathrm{Mn}^{2+}\right] \mathrm{PO}_{4}\right)$, a mixed iron-manganese phosphate mineral, indicating a phosphate component that comprises roughly one-third to one-half of the manganese in the sediment samples. Two samples from a different core, SC9 collected in April 1998, show some spectral features below $\sim 6548 \mathrm{eV}$ that can be attributed to manganese associated with sulfide, which is variable among samples and comprises from 0 to $\sim 20 \%$ of manganese in the sediments. $\dagger$ Absorption features above $6555 \mathrm{eV}$ could not be well fit with pure manganese reference compounds. The sediment samples have a second absorption maximum at $6557-6558 \mathrm{eV}$, which is near to observed maxima for $\mathrm{Mn}$ (III) and $\mathrm{Mn}$ (II,III) oxide compounds. ${ }^{25,26}$ Manganese(Iv) oxide compounds generally have absorption maxima at higher energy (6560 eV or above) (Fig. 5a). These comparisons suggest that a large fraction of manganese is bonded predominately in an oxide component as $\mathrm{Mn}$ (III) or as a mixture of $\mathrm{Mn}$ (II,III). This is consistent with substitution of manganese into detrital phyllosilicate or oxide minerals in concentrations on the order of $100-300 \mu \mathrm{g} \mathrm{g}^{-1}$ (about half of the total manganese sediment concentrations).

Iron in the sediments is a major element, occurring in concentrations of about 4-6 wt $\%$ (Fig. 3 and Table 5). Analyses of EXAFS spectra from core SC4 indicate both sulfide and oxide iron components (Fig. 5b). The sulfide component is clearly identified as pyrite based on interatomic distances derived from fits of $\mathrm{Fe}-\mathrm{S}$ and $\mathrm{Fe}-\mathrm{Fe}$ shells (Table 6). In the sediment samples, backscattering amplitudes are lower for $\mathrm{Fe}-\mathrm{S}$ and $\mathrm{Fe}-\mathrm{Fe}$ shells beyond the first sulfur coordination shell than in the crystalline pyrite reference compound (Fig. 5b). This suggests poor crystallinity and/or small particle size. ${ }^{27}$ Iron monosulfide (amorphous FeS or crystalline mackinawite), which has a different atomic structure than pyrite, ${ }^{28}$ could not be fit in the spectra. If FeS is present, it must comprise less than about 5 atom $\%$ of total iron to be undetected in the EXAFS spectra. ${ }^{22}$ Analyses of XANES spectra indicates that below $\sim 1-2 \mathrm{~cm}$ depth the primary iron oxide component in the sediment is a phyllosilicate which is most similar in structure to iron substituted into mica (e.g., illite, muscovite, or biotite). ${ }^{29}$ Other minor iron oxide components that might be present include chlorite and magnetite. Based on qualitative information from XANES spectra, the oxide component in the EXAFS spectra was fit with four shells (Table 6), Fe-O at $2.00 \AA$, Fe-Fe at 3.08-3.10 $\AA, \mathrm{Fe}-\mathrm{Si}$ at $3.26 \AA$, and $\mathrm{Fe}-\mathrm{Fe}$ at $3.39-3.42 \AA$, to account for all primary $\mathrm{Fe}-\mathrm{X}$ distances in phyllosilicates and $\mathrm{Fe}(\mathrm{III})$ oxides (if present). Based on EXAFS fits to core SC4 spectra, the relative proportion of iron in pyrite compared to oxide phases increases only slightly with depth $(\sim 3 \%)$ from 1.5 to $34.5 \mathrm{~cm}$ with no change in interatomic distances. Over this interval, total iron concentration increases from 4.4 to $5.3 \mathrm{wt} \%$.

\subsection{Reaction rates from oxidation experiments}

Trace metal dissolution during the sediment oxidation experiments are shown in Fig. 6 as the net rate and the percent metal dissolved versus time. The rates of reaction for each element were calculated according to:

$$
\text { Rate }\left(\text { day }^{-1}\right)=\Delta[\mathrm{i}]_{\mathrm{aq}} \times \mathrm{FR} \times\left(\mathrm{wt}_{\text {sediment }} \times[\mathrm{i}]_{\text {sediment }}\right)^{-1}
$$

where $\Delta[\mathrm{i}]_{\mathrm{aq}}\left(10^{-6} \mathrm{~g} \mathrm{~g}^{-1}\right)$ is the difference in concentration between the output and input (seawater blank) solutions, FR

$\uparrow$ Based on the analysis of one EXAFS spectrum, the Mn sulfide component was previously overestimated in O'Day et $a .^{22}$ Re-analyses of XANES spectra suggest at most about $20 \% \mathrm{Mn}$ sulfide in the sediments.
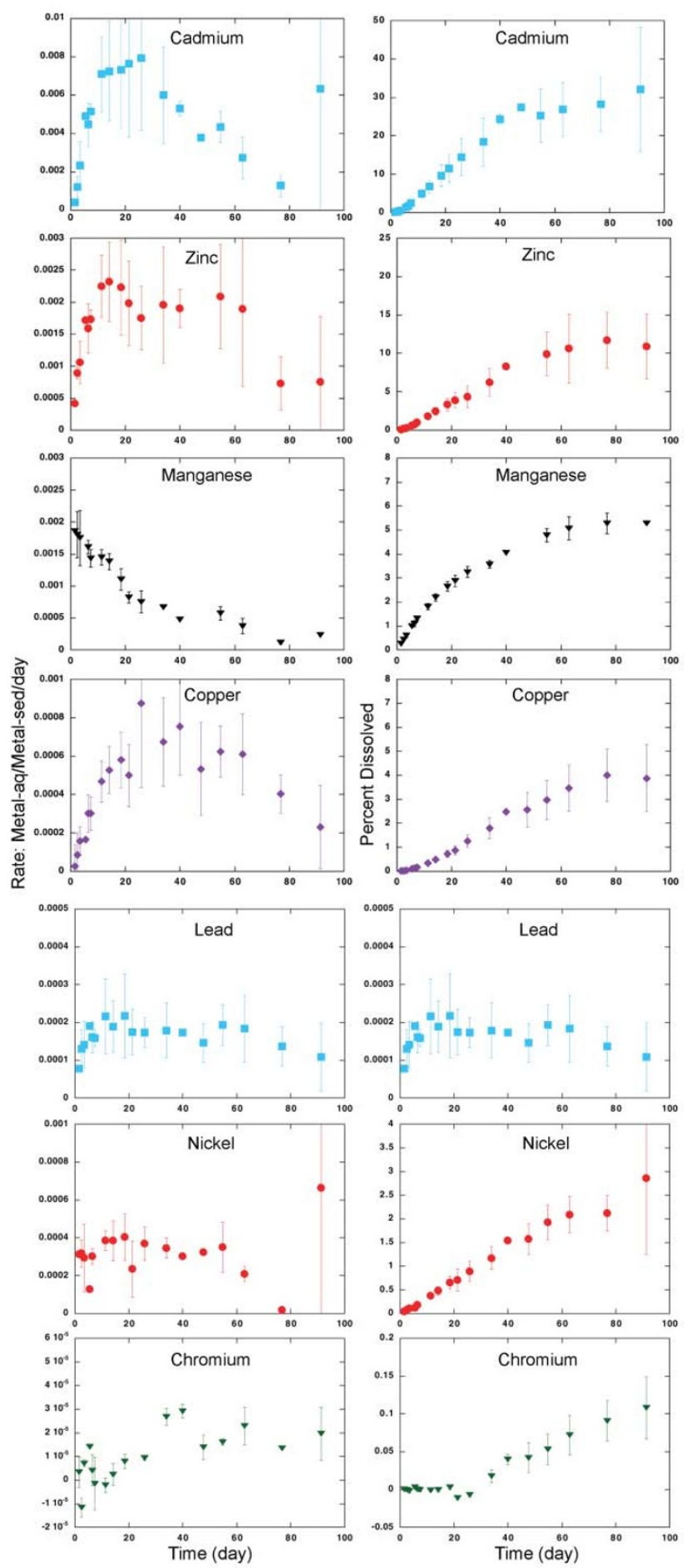

Fig. 6 Oxidation rates of reduced sediments (SC4-11) in seawater plotted as the metal concentration dissolved per day normalized to the remaining metal concentration in the sediment (right side) and as the total metal concentration dissolved normalized to the initial metal concentration in the sediment (left side).

$\left(\mathrm{g} \mathrm{day}^{-1}\right)$ is the flow rate, and $\left(\mathrm{wt}_{\text {sediment }}(\mathrm{g}) \times[\mathrm{i}]_{\text {sediment }}\right.$ $\left.\left(10^{-6} \mathrm{~g} \mathrm{~g}^{-1}\right)\right)$ is the total concentration of each element in the sediment. We use the respective seawater blank analyses as our input solutions to directly correct for any trace metal contamination from the laboratory environment as a function of time (the experiments were not conducted in a Class 100 clean room). Normalization to total concentration allows reactivity among the metals to be compared directly. We also show the total metal dissolved as the percent metal dissolved normalized to the concentration of the initial metal in the sediment versus time. The averaged rates, percent metal dissolved, and associated uncertainties are calculated from the triplicate experiments (Table 7). 
Table 7 Results of leaching experiments with sediment SC4-11 (runs A, B, C, and blank) as dissolved trace-metal concentrations ${ }^{a}$

Sediment SC4-11-A

\begin{tabular}{|c|c|c|c|c|c|c|c|c|c|c|}
\hline Sample ID & $\begin{array}{l}\text { Time/ } \\
\text { days }\end{array}$ & $\begin{array}{l}\text { Flow } \\
\text { rate/g } \\
\text { day }^{-1}\end{array}$ & $\mathrm{pH}$ & $\mathrm{Cd}(\mathrm{ppb})$ & $\mathrm{Cr}(\mathrm{ppb})$ & $\mathrm{Cu}(\mathrm{ppb})$ & $\mathrm{Mn}(\mathrm{ppb})$ & $\mathrm{Ni}(\mathrm{ppb})$ & $\mathrm{Pb}(\mathrm{ppb})$ & $\mathrm{Zn}(\mathrm{ppb})$ \\
\hline SC4-11-A-1 & 0.47 & $\mathrm{a}$ & 8.01 & $0.78 \pm 0.02$ & $0.75 \pm 0.51$ & $3.82 \pm 0.11$ & $42.5 \pm 1.6$ & $2.98 \pm 0.08$ & $1.26 \pm 0.01$ & 16.4 \\
\hline SC4-11-A-2 & 1.42 & 41.92 & 7.78 & $2.12 \pm 0.03$ & $0.44 \pm 0.24$ & $1.29 \pm 0.10$ & $22.0 \pm 0.7$ & $2.20 \pm 0.03$ & $1.92 \pm 0.02$ & $=0.10$ \\
\hline SC4-11-A-3 & 2.35 & 42.65 & 7.81 & $3.95 \pm 0.05$ & $0.24 \pm 0.13$ & $1.34 \pm 0.04$ & $17.5 \pm 0.4$ & $1.79 \pm 0.03$ & $2.67 \pm 0.03$ & $16.59 \pm 0.29$ \\
\hline SC4-11-A-4 & 3.34 & 42.97 & 7.82 & $6.50 \pm 0.09$ & $0.31 \pm$ & $1.47 \pm$ & $16.1 \pm 0.4$ & $1.42 \pm 0.04$ & $2.98 \pm 0.01$ & $17.55 \pm 0.23$ \\
\hline SC4-11-A-5 & 4.41 & 43.47 & 7.87 & na & na & na & na & na & na & na \\
\hline SC4-11-A-6 & 5.42 & 43.58 & 7.87 & na & na & na & na & na & na & na \\
\hline SC4-11-A-7 & 6.39 & 43.91 & 7.83 & $11.20 \pm 0.14$ & $0.22 \pm 0.11$ & $1.85 \pm 0.13$ & $18.7 \pm 0.8$ & $1.55 \pm 0$ & $2.84 \pm 0.01$ & 17.16 \\
\hline SC4-11-A-8 & 7.37 & 43.75 & 7.81 & na & na & na & na & na & na & na \\
\hline SC4-11-A-9 & 11.36 & 44.64 & 7.93 & $16.14 \pm 0.25$ & $0.32 \pm 0.05$ & $2.66 \pm 0.10$ & $17.7 \pm 0.4$ & $2.18 \pm 0.04$ & $2.82 \pm 0.03$ & $23.43 \pm 0.16$ \\
\hline SC4-11-A-10 & 14.19 & 45.04 & 7.82 & $13.74 \pm 0.11$ & $0.28 \pm 0.04$ & $2.68 \pm 0.12$ & $14.7 \pm 0.5$ & $1.90 \pm 0.02$ & $2.65 \pm 0.01$ & $22.48 \pm 0$. \\
\hline SC4-11-A-11 & 18.43 & 45.31 & 7.8 & $12.77 \pm 0.16$ & 0.31 & 2.64 & 12.9 & $1.92 \pm 0.04$ & $2.51 \pm 0.03$ & $18.88 \pm 0.1$ \\
\hline SC4-11-A-12 & 21.23 & 45.53 & 7.86 & $11.54 \pm 0.04$ & $0.26=$ & $2.34 \pm$ & 10.9 & 1.80 & $2.50 \pm 0.01$ & $17.41 \pm 0.2$ \\
\hline SC4-11-A-13 & 25.72 & 46.56 & 7.77 & $10.92 \pm 0.13$ & $0.39 \pm 0.28$ & $3.31 \pm 0.04$ & $10.5 \pm 0.4$ & $2.03 \pm 0.02$ & $3.01 \pm 0.01$ & $18.63 \pm 0.24$ \\
\hline SC4-11-A-14 & 33.86 & 46.91 & 7.82 & $9.45 \pm 0.11$ & $0.41 \pm 0.05$ & $2.43 \pm 0.08$ & $8.50 \pm 1.40$ & $2.00 \pm 0.04$ & $2.32 \pm 0.05$ & $12.82 \pm 0.2$ \\
\hline SC4-11-A-15 & 39.91 & 47.81 & 7.87 & na & na & & na & na & na & na \\
\hline SC4-11-A-16 & 47.75 & 41.16 & 8.05 & na & $0.38 \pm 0.09$ & $1.99 \pm 0.08$ & na & $2.21 \pm 0.30$ & $2.30 \pm 0.28$ & na \\
\hline SC4-11-A-17 & 54.75 & 44.60 & 7.81 & 10.1 & $0.44 \pm 0.11$ & $2.90 \pm 0.09$ & 8.00 & & $3.13 \pm 0.01$ & 18. \\
\hline SC4-11-A-18 & 62.91 & 44.80 & 7.85 & $6.93 \pm 0.14$ & $0.41 \pm$ & $2.39=$ & $5.90 \pm 0.90$ & $1.76 \pm 0.01$ & $2.21 \pm 0.06$ & $11.91 \pm 0.2$ \\
\hline SC4-11-A-19 & 76.90 & 48.08 & 7.87 & $2.81 \pm 0.04$ & $0.41 \pm 0.13$ & $1.77 \pm 0.04$ & $2.70 \pm 0.20$ & $1.16 \pm 0.03$ & $1.88 \pm 0.02$ & $7.58 \pm 0.08$ \\
\hline SC4-11-A-20 & 91.41 & 47.53 & 7.94 & $1.34 \pm 0.10$ & $0.36 \pm 0.21$ & $1.00 \pm 0.01$ & na & $0.88 \pm 0.02$ & $1.02 \pm 0.05$ & $3.91 \pm 0.36$ \\
\hline
\end{tabular}

Sediment SC4-11-B

\begin{tabular}{|c|c|c|c|c|c|c|c|c|c|c|}
\hline Sample ID & $\begin{array}{l}\text { Time/ } \\
\text { days }\end{array}$ & $\begin{array}{l}\text { Flow } \\
\text { rate/g } \\
\text { day }^{-1}\end{array}$ & $\mathrm{pH}$ & $\mathrm{Cd}(\mathrm{ppb})$ & $\mathrm{Cr}(\mathrm{ppb})$ & $\mathrm{Cu}(\mathrm{ppb})$ & $\mathrm{Mn}(\mathrm{ppb})$ & $\mathrm{Ni}(\mathrm{ppb})$ & $\mathrm{Pb}(\mathrm{ppb})$ & $\mathrm{Zn}(\mathrm{ppb})$ \\
\hline SC4-11-B-1 & 0.47 & $\mathrm{a}$ & 7.98 & $0.42 \pm 0.02$ & nd & $0.91 \pm 0$ & $36.9 \pm$ & $1.26 \pm 0.04$ & $1.83 \pm 0.05$ & $6.88 \pm 0.25$ \\
\hline SC4-11-B-2 & & 41.52 & 7.85 & & na & & na & & & \\
\hline SC4-11-B-3 & 2.35 & 42.12 & 7.82 & $4.89 \pm 0.05$ & nd & $1.06 \pm 0.06$ & $18.6 \pm 0.5$ & $1.86 \pm 0.05$ & $3.51 \pm 0.03$ & $13.66 \pm 0.16$ \\
\hline SC4-11-B-4 & 3.34 & 42.59 & 7.86 & $9.71 \pm 0.11$ & $0.32 \pm$ & $1.41 \pm 0.09$ & $19.1 \pm 0.7$ & $2.21 \pm 0.04$ & $3.87 \pm 0.04$ & $17.59 \pm 0.26$ \\
\hline SC4-11-B-5 & 4.41 & 43.10 & 7.86 & na & na & na & na & na & na & na \\
\hline SC4-11-B-6 & 5.42 & $\mathrm{a}$ & 7.86 & na & na & na & na & na & na & na \\
\hline SC4-11-B-7 & 6.39 & 43.73 & 7.86 & $11.59 \pm 0.13$ & $0.37 \pm 0.114$ & $2.07 \pm 0.06$ & $15.4 \pm 0.6$ & $1.45 \pm 0.05$ & $3.03 \pm 0.02$ & $19.62 \pm 0.33$ \\
\hline SC4-11-B-8 & 7.37 & 43.84 & 7.84 & $12.12 \pm 0.42$ & $0.28 \pm 0.074$ & $1.85 \pm 0.12$ & $13.8=$ & nd & $2.54 \pm 0.08$ & $19.94 \pm 1.0$ \\
\hline SC4-11-B-9 & 11.36 & 44.77 & 7.93 & 18.20 & 0.36 & & & $2.04 \pm 0.03$ & 3.69 & $23.71 \pm 0$ \\
\hline SC4-11-B-10 & 14.19 & 45.36 & 7.79 & $19.87 \pm 0.15$ & $0.37=$ & $2.85 \pm 0.12$ & 12.7 & $2.12 \pm 0.07$ & $3.72 \pm 0.05$ & $24.53 \pm 0.1$ \\
\hline SC4-11-B-11 & 18.43 & 46.43 & 7.80 & $21.20 \pm 0.24$ & $0.33 \pm 0.057$ & $3.01 \pm 0.07$ & $11.2 \pm 0.2$ & $2.25 \pm 0.04$ & $3.61 \pm 0.04$ & $24.59 \pm 0.17$ \\
\hline SC4-11-B-12 & 21.23 & 46.81 & 7.80 & 23.01 & 0.45 & & 9.16 & 2.22 & 0.04 & $22.65 \pm 0.1$ \\
\hline SC4-11-B-13 & 25.72 & 47.68 & 7.80 & $18.43 \pm 0.29$ & $0.33 \pm 0.276$ & $2.66 \pm 0.11$ & $6.17 \pm 0.37$ & $2.17 \pm 0.06$ & $2.99 \pm 0.06$ & $19.27 \pm 0.32$ \\
\hline SC4-11-B-14 & 33.86 & 48.92 & 7.81 & $14.20 \pm 1.41$ & $0.38 \pm 0.050$ & $2.66 \pm 0.10$ & na & $1.85 \pm 0.04$ & $3.09 \pm 0.29$ & $22.52 \pm 3$. \\
\hline SC4-11-B-15 & 39.91 & 50.83 & 7.86 & $8.27 \pm 0.09$ & 0.37 & $3.31 \pm 0.07$ & $3.73 \pm 0.22$ & $1.61 \pm 0.01$ & $2.62 \pm 0.07$ & $15.25 \pm 0.25$ \\
\hline SC4-11-B-16 & 47.75 & 41.34 & 7.86 & $7.42 \pm$ & $0.42 \pm$ & $2.35 \pm 0.06$ & na & $1.84 \pm 0.13$ & $3.11 \pm 0.35$ & na \\
\hline SC4-11-B-17 & 54.75 & 44.49 & 7.79 & $7.74 \pm 0.28$ & $0.40 \pm 0.112$ & $2.61 \pm 0.11$ & $4.60 \pm 0.54$ & $1.70 \pm 0.05$ & $3.68 \pm 0.10$ & $19.64 \pm 1$ \\
\hline SC4-11-B-18 & 62.91 & 44.76 & 7.80 & & & & na & $1.46 \pm 0.05$ & $3.36 \pm 0.23$ & $15.42 \pm 2$ \\
\hline SC4-11-B-19 & 76.90 & 42.20 & 7.87 & $3.49 \pm 0.06$ & $0.38 \pm 0.134$ & $2.08 \pm 0.06$ & $2.28 \pm 0.14$ & $1.10 \pm 0.04$ & $2.57 \pm 0.06$ & $8.68 \pm 0.12$ \\
\hline SC4-11-B-20 & 91.41 & 49.85 & 7.87 & $15.2 \overline{4} \pm 0.29$ & $0.46 \pm 0.214$ & $1.84 \pm 0.03$ & $2.83 \pm 0.42$ & $4.16 \pm 0.05$ & $2.62 \pm 0.21$ & $13.79 \pm 0.36$ \\
\hline
\end{tabular}

Sediment SC4-11-C

\begin{tabular}{|c|c|c|c|c|c|c|c|c|c|c|}
\hline Sample ID & $\begin{array}{l}\text { Time/ } \\
\text { days }\end{array}$ & $\begin{array}{l}\text { Flow } \\
\text { rate/g } \\
\text { day }^{-1}\end{array}$ & $\mathrm{pH}$ & $\mathrm{Cd}(\mathrm{ppb})$ & $\mathrm{Cr}(\mathrm{ppb})$ & $\mathrm{Cu}(\mathrm{ppb})$ & $\mathrm{Mn}(\mathrm{ppb})$ & $\mathrm{Ni}(\mathrm{ppb})$ & $\mathrm{Pb}(\mathrm{ppb})$ & $\mathrm{Zn}(\mathrm{ppb})$ \\
\hline SC4-11-C-1 & 0.47 & $\mathrm{a}$ & 7.96 & $0.52 \pm 0.01$ & $1.00 \pm 0.51$ & $13.71 \pm 0.26$ & $43.2 \pm 1.3$ & $4.96 \pm 0.12$ & $2.13 \pm 0.02$ & $22.43 \pm 0.31$ \\
\hline SC4-11-C-2 & 1.42 & 41.64 & 7.66 & $1.15 \pm 0.01$ & $0.30 \pm 0.24$ & $2.09 \pm 0.10$ & $22.0 \pm 0.5$ & $1.97 \pm 0.06$ & $1.96 \pm 0.00$ & $10.96 \pm 0.15$ \\
\hline SC4-11-C-3 & 2.35 & 42.49 & 7.84 & $2.50 \pm 0.00$ & $0.34 \pm 0.13$ & $2.07 \pm 0.06$ & $21.2 \pm 0.5$ & $1.65 \pm 0.03$ & $2.21 \pm 0.02$ & $13.31 \pm 0.13$ \\
\hline SC4-11-C-4 & 3.34 & 43.00 & 7.85 & $4.55 \pm 0.02$ & $0.32 \pm 0.11$ & $2.02 \pm 0.07$ & $19.8 \pm 0.4$ & $1.49 \pm 0.05$ & $2.06 \pm 0.01$ & $12.71 \pm 0.13$ \\
\hline SC4-11-C-5 & 4.41 & 43.67 & 7.85 & na & na & na & na & na & na & na \\
\hline SC4-11-C-6 & 5.42 & 43.84 & 7.86 & $14.59 \pm 0.20$ & $0.45 \pm 0.07$ & $1.38 \pm 0.07$ & $17.3 \pm 0.6$ & $1.17 \pm 0.03$ & $3.97 \pm 0.03$ & $21.49 \pm 0.16$ \\
\hline SC4-11-C-7 & 6.39 & 44.19 & 7.84 & $16.04 \pm 0.06$ & $0.29 \pm 0.11$ & $1.54 \pm 0.05$ & $16.1 \pm 0.3$ & $1.67 \pm 0.06$ & $4.09 \pm 0.04$ & $21.71 \pm 0.13$ \\
\hline SC4-11-C-8 & 7.37 & 44.33 & 7.86 & $15.70 \pm 0.07$ & $0.27 \pm 0.07$ & $1.54 \pm 0.08$ & $14.1 \pm 0.4$ & na & $3.63 \pm 0.04$ & $20.65 \pm 0.23$ \\
\hline SC4-11-C-9 & 11.36 & 45.42 & 7.91 & $23.54 \pm 0.11$ & $0.28 \pm 0.05$ & $2.05 \pm 0.12$ & $13.6 \pm 0.3$ & $2.30 \pm 0.03$ & $6.34 \pm 0.05$ & $29.54 \pm 0.33$ \\
\hline SC4-11-C-10 & 14.19 & 46.02 & 7.83 & $22.85 \pm 0.24$ & $0.39 \pm 0.04$ & $2.43 \pm 0.15$ & $14.4 \pm 1.0$ & $2.33 \pm 0.08$ & $4.73 \pm 0.06$ & $31.06 \pm 0.37$ \\
\hline SC4-11-C-11 & 18.43 & 47.27 & 7.80 & $19.52 \pm 0.17$ & $0.29 \pm 0.06$ & $2.80 \pm 0.19$ & $9.88 \pm 0.21$ & $2.21 \pm 0.02$ & $6.30 \pm 0.07$ & $28.26 \pm 0.36$ \\
\hline SC4-11-C-12 & 21.23 & 47.04 & 7.74 & $19.52 \pm 0.10$ & $0.26 \pm 0.10$ & $2.97 \pm 0.06$ & $8.88 \pm 0.12$ & na & $4.18 \pm 0.03$ & $25.56 \pm 0.09$ \\
\hline SC4-11-C-13 & 25.72 & 48.10 & 7.81 & $23.94 \pm 3.95$ & $\mathrm{nd} \pm \overline{0} .28$ & $5.95 \pm 0.22$ & na & $2.07 \pm 0.11$ & $3.94 \pm 0.41$ & na \\
\hline SC4-11-C-14 & 33.86 & 50.50 & 7.86 & $13.77 \pm 0.26$ & $0.41 \pm 0.05$ & $3.73 \pm 0.14$ & $5.15 \pm 0.18$ & $2.08 \pm 0.03$ & $4.41 \pm 0.04$ & $21.81 \pm 0.11$ \\
\hline SC4-11-C-15 & 39.91 & 54.43 & 7.85 & $10.33 \pm 1.13$ & $0.43 \pm 0.04$ & $2.37 \pm 0.06$ & na & na & $2.97 \pm 0.23$ & $13.58 \pm 2.22$ \\
\hline SC4-11-C-16 & 47.75 & 39.49 & 7.89 & na & $0.51 \pm 0.09$ & $4.10 \pm 0.19$ & na & na & $4.26 \pm 0.54$ & na \\
\hline SC4-11-C-17 & 54.75 & 45.85 & 7.87 & $10.53 \pm 0.21$ & $0.40 \pm 0.11$ & $3.54 \pm 0.11$ & $5.41 \pm 0.97$ & $2.57 \pm 0.09$ & $4.59 \pm 0.15$ & $29.81 \pm 0.57$ \\
\hline SC4-11-C-18 & 62.91 & 46.58 & 7.83 & $3.61 \pm 0.07$ & $0.57 \pm 0.15$ & $3.69 \pm 0.10$ & $3.62 \pm 0.11$ & $1.76 \pm 0.04$ & $5.19 \pm 0.04$ & $24.20 \pm 0.26$ \\
\hline SC4-11-C-19 & 76.90 & 51.01 & 7.88 & $1.59 \pm 0.28$ & $0.38 \pm 0.13$ & $2.17 \pm 0.05$ & na & $1.13 \pm 0.10$ & $3.37 \pm 0.40$ & $12.89 \pm 3.12$ \\
\hline
\end{tabular}


Table 7 Results of leaching experiments with sediment SC4-11 (runs A, B, C, and blank) as dissolved trace-metal concentrations ${ }^{a}$ (continued) Blank

\begin{tabular}{|c|c|c|c|c|c|c|c|c|c|c|}
\hline Sample ID & $\begin{array}{l}\text { Time/ } \\
\text { days }\end{array}$ & $\begin{array}{l}\text { Flow } \\
\text { rate/g } \\
\text { day }^{-1}\end{array}$ & $\mathrm{pH}$ & $\mathrm{Cd}(\mathrm{ppb})$ & $\mathrm{Cr}(\mathrm{ppb})$ & $\mathrm{Cu}(\mathrm{ppb})$ & Mn (ppb) & $\mathrm{Ni}(\mathrm{ppb})$ & $\mathrm{Pb}(\mathrm{ppb})$ & $\mathrm{Zn}(\mathrm{ppb})$ \\
\hline B-2 & 1.42 & 40.14 & 8.04 & $0.202 \pm 0.003$ & $0.32 \pm 0.24$ & $1.58 \pm$ & $1.98 \pm 0.24$ & $0.88 \pm 0.02$ & $0.124 \pm 0.002$ & $6.07 \pm 0.15$ \\
\hline B-3 & 2.35 & 41.16 & 8.02 & $0.185 \pm 0.003$ & $0.46 \pm 0.13$ & $1.09 \pm 0.05$ & $1.75 \pm 0.13$ & $0.67 \pm 0.02$ & $0.089 \pm 0.002$ & $4.51 \pm 0.06$ \\
\hline B-4 & 3.34 & 41.55 & 8 & $0.120 \pm 0.002$ & $0.22 \pm 0.11$ & $0.92 \pm 0.05$ & $1.77 \pm 0.1$ & $0.75 \pm 0.02$ & $0.077 \pm 0.002$ & $4.43 \pm 0.10$ \\
\hline B-5 & 4.41 & 42.10 & 8.02 & $0.141 \pm 0.003$ & $0.29 \pm 0.17$ & $0.86 \pm 0.02$ & $1.87 \pm 0.173$ & $0.68 \pm 0.03$ & $0.075 \pm 0.002$ & $3.78 \pm 0.06$ \\
\hline B-6 & 5.42 & $\mathrm{a}$ & 7.97 & $0.127 \pm 0.005$ & $0.27 \pm 0.07$ & $0.65 \pm 0.04$ & $1.77 \pm 0.07$ & $0.73 \pm 0.04$ & $0.047 \pm 0.001$ & $2.86 \pm 0.07$ \\
\hline B-7 & 6.39 & 42.87 & 7.96 & $0.103 \pm 0.004$ & nd & $0.52 \pm 0.03$ & $1.61 \pm 0.11$ & $0.55 \pm 0.03$ & $0.041 \pm 0.001$ & $2.74 \pm 0.04$ \\
\hline B-8 & 7.37 & 42.96 & 8.1 & $0.124 \pm 0.004$ & $0.22 \pm 0.07$ & $0.50 \pm 0.03$ & $1.73 \pm 0.08$ & $0.68 \pm 0.02$ & $0.062 \pm 0.001$ & $3.28 \pm 0.04$ \\
\hline B-9 & 11.36 & 44.27 & 7.96 & $0.103 \pm 0.005$ & $0.35 \pm 0.05$ & $0.44 \pm 0.04$ & $1.72 \pm 0.05$ & $0.91 \pm 0.03$ & $0.041 \pm 0.001$ & $2.45 \pm 0.04$ \\
\hline B-10 & 14.19 & 44.61 & 8 & $0.126 \pm 0.002$ & $0.32 \pm 0.05$ & $0.46 \pm 0.03$ & $1.54 \pm 0.05$ & $0.89 \pm 0.03$ & $0.039 \pm 0.001$ & $2.75 \pm 0.02$ \\
\hline B-11 & 18.43 & 45.35 & 7.94 & $0.110 \pm 0.002$ & $0.22 \pm 0.06$ & $0.47 \pm 0.02$ & $1.69 \pm 0.06$ & $0.88 \pm 0.02$ & $0.032 \pm 0.001$ & $2.43 \pm 0.03$ \\
\hline B-12 & 21.23 & 45.53 & 8 & $0.205 \pm 0.007$ & $0.94 \pm 0.10$ & $0.76 \pm 0.04$ & $2.50 \pm 0.10$ & $1.31 \pm 0.03$ & $0.043 \pm 0.001$ & $3.00 \pm 0.04$ \\
\hline B-13 & 25.72 & 46.33 & 7.9 & $0.097 \pm 0.014$ & nd & $0.46 \pm 0.02$ & $1.68 \pm 0.28$ & $0.96 \pm 0.08$ & nd & $1.24 \pm 0.39$ \\
\hline B-14 & 33.86 & 47.11 & 7.92 & na & $0.10 \pm 0.05$ & $0.37 \pm 0.03$ & $0.70 \pm 0.05$ & $0.94 \pm 0.15$ & nd & $2.07 \pm 0.37$ \\
\hline B-16 & 47.75 & 39.18 & 7.87 & $0.107 \pm 0.017$ & $\mathrm{nd} \pm 0.09$ & $0.37 \pm 0.02$ & $1.22 \pm 0.09$ & na & $\mathrm{na} \pm 0.000$ & na \\
\hline B-17 & 54.75 & 41.97 & 7.89 & $0.107 \pm 0.017$ & $0.2 \overline{1} \pm 0.11$ & $0.43 \pm 0.03$ & $0.84 \pm 0.11$ & $0.98 \pm 0.11$ & $0.0 \overline{2} 7 \pm 0.002$ & $1.52 \pm 0.45$ \\
\hline B-18 & 62.91 & 43.29 & 8.06 & $0.097 \pm 0.014$ & $0.20 \pm 0.15$ & $0.39 \pm 0.02$ & $1.20 \pm 0.15$ & $0.98 \pm 0.09$ & nd & na \\
\hline B-19 & 76.90 & 46.33 & 8 & $0.113 \pm 0.016$ & $0.23 \pm 0.13$ & $0.44 \pm 0.03$ & $1.47 \pm 0.13$ & $1.07 \pm 0.06$ & nd & $3.47 \pm 0.65$ \\
\hline B-20 & 91.41 & 49.13 & 7.92 & $0.087 \pm 0.002$ & $0.20 \pm 0.21$ & $0.64 \pm 0.02$ & $1.26 \pm 0.21$ & $0.92 \pm 0.01$ & $0.013 \pm 0.000$ & $3.53 \pm 0.11$ \\
\hline
\end{tabular}

The net release of trace elements from the sediments is complex and metal specific. The cadmium, zinc, manganese, and copper release rates exhibit a rapid increase in dissolution rate during the initial oxidation (1 to 20 days), followed by continual decrease in release rates with time. After about 50 days of reaction, cadmium, zinc, manganese, and copper dissolution slows to about $30,10,5$, and $4 \%$ of their respective initial sediment concentrations. After 90 days of reaction, the cadmium, zinc, manganese, and copper concentrations in the output solutions are near their respective concentrations in the top core section $(1.5 \mathrm{~cm}$, Table 2$)$. The observed non-steady state dissolution behavior is indicative of concurrent dissolution of a reduced solid phase and precipitation of a stable secondary phase that limits the transfer of the trace metals to oxygen-rich seawater.

The net release rates of nickel, lead, and chromium are 10 to 100 times lower than the release rates of cadmium, zinc, manganese, and copper. Additionally the rates are more or less constant as a function of time, and show steady-state reaction kinetics. Nickel release rates are constant within the scatter of the data with the exception of one outlying data point at about 80 days. Lead release rates increase slightly during the first 10 days, are constant for the next 50 to 60 days, and decrease slightly after 80 days. Chromium release is characterized by minimal dissolution during the first 25 days followed by slightly greater dissolution rates that are constant for the duration of the experiment. These metals dissolve slowly with time; about $3 \%$ of the initial nickel, $1 \%$ of the initial lead and $0.1 \%$ of the initial chromium dissolve after the reduced sediments have reacted with seawater for 90 days.

For aluminium, calcium, potassium, iron, magnesium, and silica we observed minimal reactivity. There were no changes in the calcium, potassium and magnesium input and output concentrations. The dissolved iron, aluminium, and silica concentrations in the output solutions are below the analytical detection limits. This is expected because quartz, phyllosilicates, and iron oxides have very low dissolution rates in near-neutral seawater.

\subsection{XAS analysis of metals in oxidized sediments}

At the end of the 90 day oxidation experiment (SC4-11, $31.5 \mathrm{~cm}$ ), sediments were re-examined with XAS to evaluate changes in oxidation state and local coordination compared to unreacted core sediments from similar depth. Cadmium, which was entirely coordinated by sulfur in unreacted sediments, is partially coordinated by oxygen in the reacted sample (Fig. 7a). Analyses of the EXAFS spectrum showed about $47 \%$ atomic coordination by oxygen and $53 \%$ coodination by sulfur. The interatomic $\mathrm{Cd}-\mathrm{S}$ distances are identical to those of cadmium in unreacted sediments, indicating that the original CdS phase has not completely dissolved (Table 6). The $\mathrm{Cd}-\mathrm{O}$ distance in the oxide component derived from EXAFS analysis (2.31 $\AA$ ) is typical of cadmium oxide phases and oxygen-coordinated sorption complexes. ${ }^{16,30,31}$ However, the lack of backscattering atoms beyond the first coordination shell suggests that the $\mathrm{Cd}-\mathrm{O}$ component is not a well crystallized solid.

The X-ray absorption spectrum for zinc of the reacted sample likewise shows conversion of the original sulfide phase to an oxide phase (Fig. 7b). In unreacted sample SC4-12, 78\% of zinc was coordinated by sulfur with local structure indicative of poorly crystalline sphalerite $(\mathrm{ZnS})$. In reacted sample SC4$11,25 \%$ of zinc remains coordinated in $\mathrm{ZnS}$ (distances are identical to unreacted samples) and $75 \%$ of zinc is coordinated by oxygen. As discussed previously, the original zinc oxide component may be a composite of zinc substituted into detrital silicate and oxide phases. These phases are probably recalcitrant during reaction with seawater and would not dissolve significantly. The absorption spectrum of the reacted sample is therefore a composite of residual $\mathrm{ZnS}$, the original oxide component(s), and a new zinc oxide component. Least-squares fits of the EXAFS spectrum of the reacted sample indicate a first shell of oxygen atoms at an average distance of $2.03 \AA$ and metal backscatterers at $3.13 \AA$, similar to unreacted samples (Table 6). There is also evidence for metal backscatterers at a longer distance $(3.39 \AA)$ which is indicative of corner sharing of metal octahedra or tetrahedra in (oxy)hydroxides and phyllosilicates. Owing to the complicated signal, backscattering in the oxide component could not be fit with unique elements beyond the coordinating shell of oxygen atoms. The interatomic distances obtained from fits, however, are consistent with zinc association with iron (oxy)hydroxide or phyllosilicate phases in addition to the original zinc oxide components (Fig. 7b).

In contrast to sulfide-associated metals, the XAS spectra 
(a)

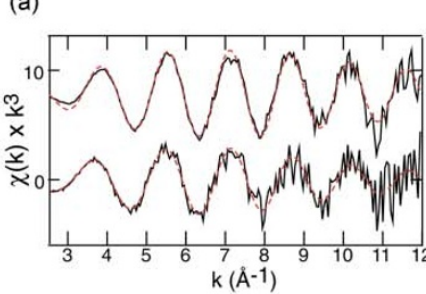

(b)
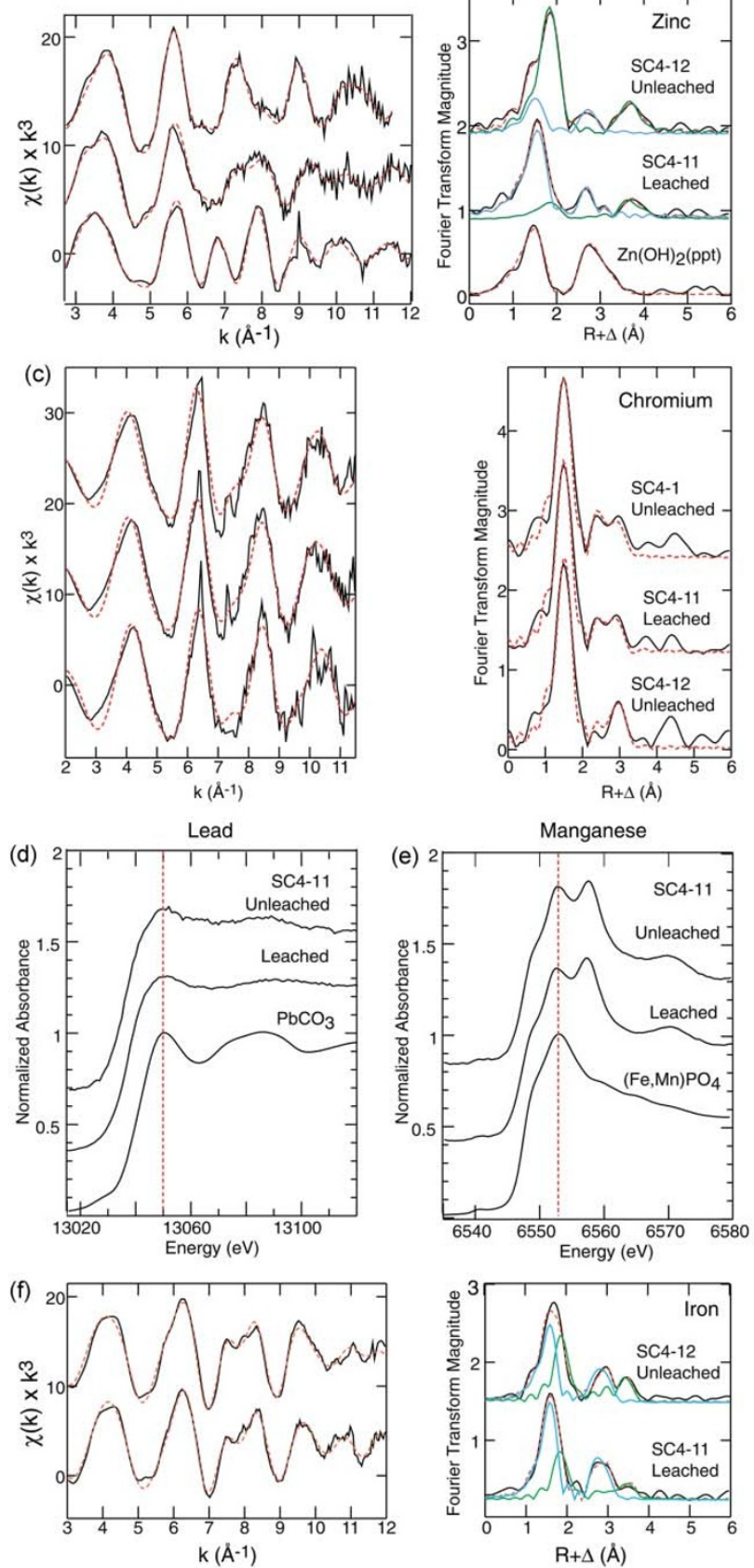

Fig. 7 (a) Normalized EXAFS and corresponding radial structure functions (uncorrected for phase shift of backscattering atoms) for cadmium in unleached and leached sediment samples from core SC4 at approximately the same depth $(34 \mathrm{~cm})$. Dashed red line is the nonlinear least-squares best fit; green line is the fit component corresponding to CdS; blue line is the fit for a cadmium-oxygen component that probably represents cadmium adsorption on iron (oxy)hydroxides that form from pyrite oxidation. (b) Normalized EXAFS and corresponding radial structure functions (uncorrected for phase shift of backscattering atoms) for zinc in unleached and leached sediment samples from core SC4. Dashed red line is the non-linear least-squares best fit; green line is the fit component corresponding to sphalerite; blue line is the fit for a zinc-oxygen component that probably represents zinc adsorption on iron (oxy)hydroxides that form from of metals primarily associated with oxide phases show little change after reaction with seawater. There is no evidence in the chromium XAS data (XANES or EXAFS spectrum) for oxidation to $\mathrm{Cr}(\mathrm{vI})$, although a small percentage $(<5$ atom $\%)$ of surface-oxidized chromium cannot be ruled out based on the bulk spectrum. The EXAFS spectrum of the reacted sample most closely resembles that of the shallow sediment sample SC4-1 $(1.5 \mathrm{~cm})$ and differs slightly from that of sample SC4-12 $(34.5 \mathrm{~cm})$ (Fig. 7c). Fits indicate that these differences are related to the number of metal backscatterers beyond the first coordination shell of oxygen atoms and not to large changes in interatomic distances (Table 6). For lead and manganese, comparison of XANES spectra also indicates no signficant changes in local atomic coordination after reaction (Fig. 7d, e).

In the leached sediment sample, analysis of the iron EXAFS spectrum indicates a reduction of $17 \%$ in the fraction of the pyrite component compared to unreacted sediment SC4-12 $(34.5 \mathrm{~cm})$ based on integrated curve areas for fit pyrite and oxide components (Fig. 7f, Table 6). It is likely that iron lost from pyrite was resorbed or reprecipitated, probably as iron (oxy)hydroxides, because at most $1 \%$ of the iron was lost to solution (dissolved iron concentrations were below the detection limit of $100 \mathrm{ng} \mathrm{g}^{-1}$ ). Analyses of the XANES spectrum of the leached sample indicates an small increase in the amount of $\mathrm{Fe}(\mathrm{III})$. Interatomic distances of the oxide component do not show any significant changes between reacted and unreacted sediments because distances among second-neighbor backscattering atoms in phyllosilicates and iron (oxy)hydroxides overlap (in the range of 3.03-3.15 $\AA$ ). Backscattering amplitudes for second-neighbor atoms at 3.09-3.10 $\AA$ are higher in the leached sample compared to unleached samples, perhaps indicative of the precipitation of (oxy)hydroxides. At the $\mathrm{pH}$ of the leaching experiment $(\mathrm{pH}=7.9)$, we expect minimal dissolution of phyllosilicates and quartz, precluding sources of aluminium and silica. The mostly likely phase for iron reprecipitation is amorphous iron (oxy)hydroxides.

\section{Discussion}

\subsection{Trace metal geochemistry in estuarine sediments}

The sediment cores represent a 60 year record of metal contamination in the Seaplane Lagoon as determined by ${ }^{137} \mathrm{Cs}$, ${ }^{26} \mathrm{Ra}$, and ${ }^{210} \mathrm{~Pb}$ analyses of gravity cores collected at the same location and time as our sediment cores. ${ }^{32}$ Comparison of XANES and EXAFS spectra from suboxic sediments at $1.5 \mathrm{~cm}$ depth and anoxic sediments at $34.5 \mathrm{~cm}$ (and deeper) suggest that most of the important trace metal chemistry occurs near the sediment-water interface and/or in the suboxic zone, where metal contaminates are strongly partitioned to sulfide or oxide phases. Once buried in the anoxic zone, the metal host phases are stable for long periods of time. X-ray absorption spectra

pyrite oxidation and zinc substitution in phyllosilicate or oxide minerals noted previously. (c) Normalized EXAFS and corresponding radial structure functions (uncorrected for phase shift of backscattering atoms) for chromium in unleached and leached sediment samples from core SC4. Dashed red line is the non-linear least-squares best fit. (d) Normalized XANES spectra for lead in samples in unleached and leached sediment from core SC4 compared to reference crystalline lead carbonate $\left(\mathrm{PbCO}_{3}\right)$. (e) Normalized XANES spectra for manganese in samples in unleached and leached sediment from core SC4 compared to a reference manganese phosphate $\left(\mathrm{Fe}, \mathrm{Mn}\left(\mathrm{PO}_{4}\right)\right)$. (f) Normalized EXAFS and corresponding radial structure functions (uncorrected for phase shift of backscattering atoms) for iron in unleached and leached sediment samples from core SC4. Dashed red line is the non-linear least-squares best fit; green line is the fit component corresponding to pyrite; blue line is the fit for an iron-oxygen component that probably represents formation of an iron (oxy)hydroxide in addition to iron substitution in phyllosilicate or oxide minerals discussed previously. 
of shallow and deep sediments show that poorly crystalline cadmium and zinc sulfides form during biologically mediated sulfate reduction in the suboxic zone and remain stable in sediments with high $\mathrm{HS}^{-}$concentrations for at least 50 to 60 years (to depths of $55 \mathrm{~cm}$ in deep cores). Thermodynamic calculations show porewater saturation or supersaturation with respect to both cadmium and zinc sulfide. Because of the high dissolved $\mathrm{HS}^{-}$concentrations, metal sulfide aqueous complexes for several trace metals are stable and produce higher aqueous concentrations of contaminants with depth.

Similarly, we infer that association of lead with carbonate or phosphate phases, manganese with phosphate, and chromium with oxides or phyllosilicates occurs within the water column, the thin oxic sediment zone, or within the suboxic zone. X-ray absorption data show that the local atomic structure around these elements is independent of depth to $34.5 \mathrm{~cm}$, suggesting association with thermodynamically stable or recalcitrant phases. Although the porewaters are saturated with respect to galena $(\mathrm{PbS})$, there is no evidence for lead associated with sulfides in the XAS spectra. Lead may substitute for calcium in either calcite or apatite, both of which are thermodynamically stable based on porewater concentrations, or it may be present as a sorbed complex. Likewise, XANES spectra show that manganese is partially associated with a phosphate phase, which may indicate substitution in apatite or formation of $\mathrm{MnHPO}_{4}(\mathrm{~s})$ as porewaters are close to $\mathrm{MnHPO}_{4}(\mathrm{~s})$ saturation $(\log \mathrm{SI}=-1)$. As one might expect, chromium is present only as $\mathrm{Cr}$ (III) in these highly reduced sediments. XAS data suggest that dissolved anthropogenic chromium is removed from porewater by either precipitation of chromite or by sorption of chromium to phyllosilicates in the sediments. This is consistent with laboratory observations of $\mathrm{Cr}$ (III) sorption to micas and of the reduction of sorbed $\mathrm{Cr}$ (VI) by $\mathrm{Fe}(\mathrm{II})$ bearing micas. ${ }^{33}$ The EXAFS data and the solution chemistry are also consistent with chromium association with oxides such as eskolaite, chromite or magnesiochromite, all of which are supersaturated. It is doubtful that chromium, lead, and manganese could be sorbed to iron (oxy)hydroxides below the oxic zone (about 1-2 cm) because XANES analysis indicates that available $\mathrm{Fe}(\mathrm{III})$ is not present below that depth. ${ }^{29}$ Consequently, any chromium, lead, or manganese sorbed to iron (oxy)hydroxides in the water column or the oxic sediments would desorb and bond with oxides, phyllosilcates, carbonates, or phosphates below the zone of $\mathrm{Fe}(\mathrm{III})$ reduction.

Detrital phyllosilicates and oxides comprise a recalcitrant fraction of metals in these sediments. This conclusion is based on direct spectroscopic evidence, metal concentration profiles, and by comparison with metal concentrations in uncontaminated San Francisco Bay sediments. ${ }^{21}$ The authigenic source of metals to San Francisco Bay sediments is the weathering of the ultramafic Franciscan formation, which can be seen in the iron and zinc oxide components. The iron oxide component is best described as recalcitrant phyllosilicate and oxide phases, probably as iron-bearing micas such as illite, muscovite, chlorite or biotite and oxides such as magnetite, chromite, or ilmenite $^{18}$ that do not dissolve in the strongly reducing sediments at neutral $\mathrm{pH}$. It is likely that the zinc oxide fraction and part of the chromium and manganese fractions are associated with these unreactive phases. Comparison of the metal concentrations in the oxide components and in the surface sediments with metal concentrations in uncontaminated San Francisco Bay sediments further supports the detrital source for metals. Hornberger et al. ${ }^{21}$ report background chromium concentrations of 125 to $150 \mu \mathrm{g} \mathrm{g}^{-1}$, copper concentrations of 20 to $40 \mu \mathrm{g} \mathrm{g}^{-1}$, lead concentrations of $5 \mu \mathrm{g} \mathrm{g}^{-1}$, nickel concentrations of 75 to $100 \mu \mathrm{g} \mathrm{g}^{-1}$, and zinc concentrations of $78 \mu \mathrm{g} \mathrm{g}^{-1}$. These numbers compare well with zinc concentrations associated with the zinc oxide component estimated from EXAFS (50 to $130 \mu \mathrm{g} \mathrm{g}^{-1}$ ), and surface sediment chromium $\left(200 \mu \mathrm{g} \mathrm{g}^{-1}\right)$, copper $\left(100 \mu \mathrm{g} \mathrm{g}^{-1}\right)$, and nickel $\left(100 \mu \mathrm{g} \mathrm{g}^{-1}\right)$ concentrations. We cannot resolve the anthropogenic and detrital chromium components in the EXAFS, but the data are consistent with a partial detrital component. Seaplane Lagoon nickel and manganese concentrations are fairly constant and do not show the anthropogenic signature of increasing concentration with depth that is seen for the other trace metals. Therefore, it is possible that nickel and the non-phosphate manganese fraction are associated with detrital phyllosilicates. Almost all of the lead in the sediments is anthropogenic even in the surface sediments. Lead concentrations in the Seaplane Lagoon sediments range from 200 to $1400 \mu \mathrm{g} \mathrm{g}^{-1}$, and are 40 to 280 times higher than in the uncontaminated San Francisco Bay sediments.

\subsection{Metal geochemistry in oxidized sediments}

Oxidation of reduced estuarine sediments may occur during dredging operations and during bioturbation or storm events at the interface between the surface sediments and the overlying water. In these environments, the oxidation of sulfides is an important source of dissolved cadmium, zinc, and possibly copper. However, their inherent hazard to biota is mitigated by their sorption to or co-precipitation with oxide substrates. Of these trace metals, cadmium is the most mobile because much less of it is precipitated as an oxide. In our study, about $63 \%$ of the $\mathrm{CdS}$ and $71 \%$ of the $\mathrm{ZnS}$ in the reduced sediments dissolved during the experiment, but only $50 \%$ of the reacted cadmium was taken up as an oxide, compared to $80 \%$ of the reacted zinc. These numbers are based on comparison of EXAFS analyses of the reduced and oxidized sediment, and on the net amount of metal dissolved during the experiment (Fig. 6 and 7). One explanation for the low uptake of cadmium compared to zinc is much higher cadmium aqueous complexation. In seawater, about $99 \%$ of the cadmium complexes with chloride and 1\% is free cadmium ion. By contrast, only $32 \%$ of the zinc complexes with chloride and $58 \%$ is free zinc ion. This comparison suggests that free metal ions have much higher affinity for hydroxide surfaces than the metal complexes. Minimal cadmium sorption may also result from competition between zinc and cadmium. This phenomenon has been observed in laboratory and field studies. In laboratory experiments, cadmium sorption was suppressed by zinc and lead sorption to iron oxyhydroxide. ${ }^{34,35}$ A field study of mine drainage sediments showed that iron (oxy)hydroxide effectively sorbs zinc. ${ }^{16,36}$ We assume that copper is present as a sulfide at depth and sorbs to an oxide substrate when the sediment is oxidized, because the dissolution of copper with time is similar to the behavior of cadmium and zinc. All three elements exhibit a rapid increase in the dissolution rate followed by a decrease in the rate as they sorb to or co-precipitate with oxide substrates.

The most likely oxide substrate for cadmium and zinc uptake is precipitated iron (oxy)hydroxide from the dissolution of pyrite during the oxidation experiment. Pyrite is known to dissolve in seawater. Morse ${ }^{37}$ report $20 \%$ oxidation of pyrite in seawater in one day. In our EXAFS spectra, we detected a $17 \%$ decrease in the pyrite fraction at the end of our oxidation experiment. It is likely that the decrease in the pyrite fraction was accompanied by the precipitation of an iron (oxy)hydroxide because almost no dissolved iron was measured in the oxidation experiments. Another possible oxidesubstrate for cadmium and zinc uptake would be phyllosilicate phases present in the sediments. It is doubtful that cadmium and zinc co-precipitates with calcium carbonate because no calcite was detected in the X-ray diffraction patterns, nor do we have evidence from solution chemistry for calcite precipitation during the oxidation experiment. It is also doubtful that cadmium and zinc sorb to manganese (oxy)hydroxides because the concentrations of cadmium $\left(\sim 40 \mu \mathrm{g} \mathrm{g}^{-1}\right)$ and zinc $\left(\sim 210 \mu \mathrm{g} \mathrm{g}^{-1}\right)$ associated with the oxide component 
approximate the total manganese $\left(\sim 210 \mu \mathrm{g} \mathrm{g}^{-1}\right)$ in nonphosphate component ( $\sim 50-80 \%$, which is probably associated with phyllosilicates). The non-phosphate and phosphate manganese components are stable in seawater. Although a small percentage of manganese dissolved during the first few hours of oxidation, no significant changes in the relative proportions of these phases were observed in the XANES spectra.

Oxidation of reduced contaminated sediments will not yield significant mobilization of chromium and lead because they are associated with oxides, phyllosilicates, carbonates or phosphates. Consequently, they are stable when exposed to oxygen-rich seawater and exhibit little dissolution. Additionally chromium retains its reduced oxidation state as $\mathrm{Cr}(\mathrm{III})$ when reacted with seawater. Although there is little difference in XAS spectra for the reduced and oxidized sediments, we cannot rule out the possibility that chromium and lead desorb and are taken up by the iron (oxy)hydroxides that forms as pyrite oxidizes.

\section{Conclusions}

The fate of metal contaminants in urban harbor and coastal sediments depends on the form of the stable solid phase that hosts the metal as sediments are buried and reduced, which cannot necessarily be predicted from the water chemistry. In the suboxic and anoxic sediments with elevated $\mathrm{HS}^{-}$concentrations, anthropogenic cadmium and zinc form disordered sulfides, but anthropogenic lead and chromium are associated with stable oxides. In addition to the anthropogenic metals, some chromium, manganese, and zinc and all of the nickel appear to be associated with recalcitrant detrital minerals, quite possibly in iron-rich phyllosilicates and oxides. A fraction of manganese is also present as a phosphate. Cadmium and zinc pose the greatest hazard to biota during dredging, bioturbation, or storm events because these sulfides are unstable and will dissolve in oxygen-rich seawater. Dissolved cadmium and zinc will partially sorb to available phyllosilicates or oxides, or co-precipitate with iron (oxy)hydroxides that form as pyrite oxidizes. Uptake of cadmium and zinc by oxides significantly lowers their dissolved concentrations and reduces their overall hazard to biota. Dredging of deeper sediments poses a minimal hazard to biota for lead and chromium because they are associated with stable carbonate, phosphate, phyllosilicates or oxides. Additionally, chromium is present in its reduced from, $\mathrm{Cr}(\mathrm{III})$, in the sediments and showed no evidence for oxidation to $\mathrm{Cr}(\mathrm{VI})$ when reacted with seawater.

One significant observation from this study is that dominant reactions that remove dissolved metals from solution occur within the water column or the oxic and suboxic sediments, with minimal metal transformation within the anoxic sediments over time (and depth). As iron (oxy)hydroxides and sulfate are reduced at depths less than $5 \mathrm{~cm}$, dissolved metals are taken-up by stable solids below the sediment-water interface. Once buried, the phases hosting the trace metals are stable for a minimum of 60 years (age of the sediments). Any cadmium and zinc associated with reactive iron (oxy)hydroxides in the water column or in the oxic sediments will dissolve and re-precipitate as disordered sulfides with in suboxic sediments. In contrast, any lead bonded to stable phases such carbonate or phosphate in the oxygen-rich water column or in oxic sediments does not dissolve and reprecipitate as its thermodynamically stable sulfide phase (galena, $\mathrm{PbS}$ ).

This work was motivated by the US Navy's concern that sediments contaminated prior to the Clean Water Act (1975) would contaminate the overlying water column as metals dissolve when reduced sediments react with oxygen-rich water during bioturbation, storm, dredging and other marina activities. The results of this study can be used to help design the impact of remediation strategies.

\section{Acknowledgements}

This work was supported by Alameda Naval Air Station BERC, University of California at Berkeley and was performed under the auspices of the Department of Energy by the Lawrence Livermore National Laboratory under Contract W-7405-Eng-48. Work at Arizona State University was done under subcontract B338664 from LLNL and supported by the National Science Foundation (EAR-9629276 to PAO). The XAS work was done at SSRL, which is operated by the DOE, Office of Basic Energy Sciences. We thank the SSRL Biotechnology Program, which is supported by the National Institutes of Health, National Center for Research Resources, Biomedical Technology Program, and the DOE, Office of Biological and Environmental Research. We thank Andrew Bono for assistance with sample and XAS data collection, Patrick Allen and Jerry Bucher for use of their Ge detector, Roger Martinelli for assistance with porewater analysis, and Ron Pletcher for assistance with processing of the sediment cores.

\section{References}

1 The Incidence and Severity of Sediment Contamination in Surface Waters of the United States. Volume 1. National Sediment Quality Survey, Environmental Protection Agency, 1997, \#EPA 823-R-97006.

2 Draft EIR: For the reuse of Naval Air Station Alameda and the Fleet and Industrial Supply Center, Alameda Annex and Facility, Alameda, California, City of Alameda, Alameda, 1999.

3 I. Rivera-Duarte and A. R. Flegal, Benthic lead fluxes in San Francisco Bay, California, USA, Geochim. Cosmochim. Acta, 1994, 58, 3307-3313

4 I. Rivera-Duarte and A. R. Flegal, Pore-water silver concentration gradients and benthic fluxes from contaminated sediments of San Francisco Bay, California, USA, Mar. Chem., 1997, 56, 15-26.

5 I. Rivera-Duarte and A. R. Flegal, Porewater gradients and diffusive benthic fluxes of $\mathrm{Co}, \mathrm{Ni}, \mathrm{Cu}, \mathrm{Zn}$, and $\mathrm{Cd}$ in San Francisco Bay, Croat. Chim. Acta, 1997, 70, 389-417.

6 S. F. G. Westerlund, L. G. Anderson, P. O. J. Hall, A. Iverfeldt, M. M. R. van der Loeff and B. Sundby, Benthic fluxes of cadmium, copper, nickel, zinc, and lead in the coastal environment, Geochim. Cosmochim. Acta, 1986, 50, 1289-1296.

7 B. Sunby, L. G. Anderson, P. O. J. Hall, A. Iverfeldt, M. M. R. van der Loeff and S. F. G. Westerlund, The effect of oxygen on release and uptake of cobalt, manganese, iron, and phosphate at the sediment-water interface, Geochim. Cosmochim. Acta, 1986 50, 1281-1288.

8 W. A. Kornicker and J. W. Morse, Interactions of divalent cations with the surface of pyrite, Geochim. Cosmochim. Acta, 1991, 55, 2159-2171.

9 M. A. Huerta-Diaz and J. W. Morse, Pyritization of trace metals in anoxic marine sediments, Geochim. Cosmochim. Acta, 1992, 56, 2681-2702.

10 T. Arakaki and J. W. Morse, Coprecipitation and adsorption of $\mathrm{Mn}$ (II) with mackinawite (FeS) under conditions similar to those found in anoxic sediments, Geochim. Cosmochim. Acta, 1993, 57, 9-14.

11 C. A. Coles, S. R. Rao and R. N. Yong, Lead and cadmium interactions with mackinawite: Retention mechanisms and the role of pH, Environ. Sci. Technol., 2000, 34, 996-1000.

12 K. G. Knauss and T. J. Wolery, Dependence of albite dissolution kinetics on $\mathrm{pH}$ and time at $25^{\circ} \mathrm{C}$ and $70{ }^{\circ} \mathrm{C}$, Geochim. Cosmochim. Acta, 1986, 50, 2481-2497.

13 J. W. Boyle and E. A. Wu, Low blank preconcentration technique for the determination lead, copper, and cadmium in small-volume seawater by isotope dilution ICPMS, Anal. Chem., 1997, 69, 2464 2470 .

14 G. N. George and I. J. Pickering, EXAFSPAK: A suite of computer programs for analysis of X-ray absorption spectra, 1993, Stanford Synchrotron Radiation Laboratory, Palo Alto, CA.

15 J. J. Rehr, R. C. Albers and S. I. Zabinsky, High-order multiple scattering calculations of X-ray absorption fine structure, Phys. Rev. Lett., 1992, 69, 3397-3400. 
16 P. A. O'Day, S. A. Carroll and G. A. Waychunas, Rock-water interactions controlling zinc, cadmium, and lead in surface waters and sediments: I. Molecular identification using X-ray absorption spectroscopy, Environ. Sci. Technol., 1998, 32, 943-955.

17 S. Carroll, B. Esser, S. Randal, P. O'Day, A. Bono and G. W. Luther, III, Geochemical Characterization of Seaplane Lagoon Sediments, Alameda Naval Air Station, California, LLNLUCRL-ID-135193, Lawrence Livermore National Laboratory, Livermore, CA, 1999.

18 P. A. O'Day, N. Rivera and S. A. Carroll, X-ray Absorption Spectroscopy Study of Iron Reference Compounds for the Analysis of Natural Sediments. in preparation.

19 C. M. Bethke, The Geochemist's Workbench: A users guide to Rxn, Act2, Tact, React, and Gtplot, University of Illinois, UrbanaChampaign, IL, 2nd edn., 1994, p. 213.

20 J. W. Johnson, E. H. Oelkers and H. C. Helgeson, SUPCRT92: A softwater package for calculating the standard molal thermodynamic properties of minerals, gases, aqueous species, and reactions from 1 to 5000 bar and 0 to $1000{ }^{\circ} \mathrm{C}$, Comput. Geosci., 1992, 18, 899-947.

21 M. I. Hornberger, S. N. Luoma, A. van Geen, C. Fuller and R. Anima, Historical trends of trace metals in the sediments of San Francisco Bay, California, Mar. Chem., 1999, 64, 39-55.

22 P. A. O’Day, S. A. Carroll, S. Randall, R. E. Martinelli, S. L. Anderson, J. Jelinski and J. Knezovich, Metal Speciation and Bioavailability in Contaminated Estuary Sediments, Alameda Naval Air Station, California, Environ. Sci. Technol., 2000, 34, 3665-3673.

23 J. R. Barger, G. E. Brown, Jr. and G. A. Parks, Surface complexation of $\mathrm{Pb}(\mathrm{II})$ at oxide-water interfaces: XAFS and bound-valence determination of mononuclear $\mathrm{Pb}$ (II) sorption products and surface functional groups on iron oxides, Geochim. Cosmochim. Acta, 1997, 61, 2639-2652.

24 J. D. Ostergren, G. E. Brown Jr., G. A. Parks and T. N. Tingle, Quantitative speciation of lead in selected mine tailings from Leadville, CO, Environ. Sci. Technol., 1999, 33, 1627-1636.

25 J. E. Villinski, P. A. O’Day, T. L. Corley and M. H. Conklin, In situ spectrocopic and solution analyses of the reductive dissolution of $\mathrm{MnO}_{2}$ by $\mathrm{Fe}(\mathrm{II})$, Environ. Sci. Technol., 2001, 35, 1157-1163.

26 J. E. Villinski, Reductive dissolution of manganese (IV) oxides and precipitation of iron(III): Implications for redox processes in an alluvial aquifer affected by acid mine drainage, 2001, The University of Arizona, Tucson, AZ.

27 P. A. O'Day, G. E. J. Brown and G. A. Parks, X-ray absorption spectroscopy of cobalt(II) multinuclear surface complexes and surface precipitates on kaolinite, J. Colloid Interface Sci., 1994, 165, 269-289

28 C. Palache, H. Berman and C. Frondel, Dana's System of Mineralogy, 7 th edn., 1944, pp. 210-215

29 P. A. O'Day, S. A. Carroll, S. Randall, A. Bono and G. W. Luther (III), Iron Speciation in reduced estuarine sediments from in situ spectroscopy and microelectrode measurements, in preparation.

30 L. Spadini, A. Manceau, P. W. Schindler and L. Charlet, Structure and stability of $\mathrm{Cd}^{2+}$ surface complexes on ferric oxides 1 . Results from EXAFS spectroscopy, J. Colloid Interface Sci., 1994, 168, 73-86.

31 S. R. Randall, D. M. Sherman, K. V. Ragnarsdottir and C. R. Collins, The mechanism of cadmium surface complexation on iron oxyhydroxide minerals, Geochim. Cosmochim. Acta, 1999, 63, 2971-2987.

32 A. H. Love, B. K. Esser and J. R. Hunt, Reconstructing contaminant deposition in a San Francisco Bay Marina, J. Environ. Eng., 2002, submitted.

33 E. S. Ilton and D. R. Veblen, Chromium sorption by phlogopite and biotite in acidic solutions at $25{ }^{\circ} \mathrm{C}$ : Insights from X-ray photoelectron spectroscopy and electron microscopy, Geochim. Cosmochim. Acta, 1994, 58, 2777-2788.

34 M. M. Benjamin and J. O. Leckie, Adsorption of metals at oxide interfaces: Effects of the concentrations of adsorbate and competing metals, in Contaminants and Sediments, ed. R. A. Baker, 1980 , American Chemical Society, New York.

35 M. M. Benjamin and J. O. Leckie, Multiple-site adsorption of Cd, $\mathrm{Cu}, \mathrm{Zn}$, and $\mathrm{Pb}$ on amorphous iron oxyhydroxide, J. Colloid Interface Sci., 1981, 79, 209-221.

36 S. A. Carroll, P. A. O'Day and M. Piechowski, Rock-water interactions controlling zinc, cadmium, and lead concentrations in surface waters and sediments: II. Geochemical interpretation, Environ. Sci. Technol., 1998, 32, 956-965.

37 J. W. Morse, Oxidation kinetics of sedimentary pyrite in seawater, Geochim. Cosmochim. Acta, 1991, 55, 3665-3667.

38 V. A. Pokrovskii and H. C. Helgeson, Thermodynamic properties of aqueous species and the solubilities of minerals at high pressures and temperatures: The system $\mathrm{Al}_{2} \mathrm{O}_{3}-\mathrm{H}_{2} \mathrm{O}-\mathrm{NaCl}, A m$. J. Sci., 1995, 295, 1255-1342.

39 H. C. Helgeson, J. M. Delany, H. W. Nesbitt and D. K. Bird, Summary and critique of the thermodynamic properties of rockforming minerals, Am. J. Sci., 1978, 278-A, 1-229

40 R. A. Robie, B. S. Hemingway and J. S. Fisher, Thermodynamic properties of minerals and related substances at $298.15 \mathrm{~K}$ and 1 bar (105 Pascals) pressure and at higher temperatures, US Geol. Survey Bull., 1979, 1452, 1-456.

41 C. F. J. Baes and R. E. Mesmer, The Hydrolysis of Cations, WileyInterscience, New York, 1976.

42 D. A. Sverjensky, E. L. Shock and H. C. Helgeson, Prediction of the thermodynamic properties of aqueous metal complexes to 1000 degrees C and 5 kb, Geochim. Cosmochim. Acta, 1997, 61, 13591412.

43 S. L. S. Stipp, G. A. Parks, D. K. Nordstrom and J. O. Leckie, Solubility-product constant and thermodynamic properties for synthetic otavite, $\mathrm{CdCO}_{3}(\mathrm{~s})$, and aqueous association constants for the $\mathrm{Cd}(\mathrm{II})-\mathrm{CO}_{2}-\mathrm{H}_{2} \mathrm{O}$ system, Geochim. Cosmochim. Acta, 1993, 57, 2699-2714.

44 D. D. Wagman, W. H. Evans, V. B. Parker, R. H. Schumm, I. Halow, S. M. Bailey, K. L. Churney and R. L. Nuttall, The NBS tables of chemical themodynamic properties, J. Phys. Chem. Ref. Data, 1982, 11(suppl. 2),

45 R. Al-Farawati and C. M. G. van den Berg, Metal-sulfide complexation in seawater, Mar. Chem., 1999, 63, 331-352.

46 J. D. Cox, D. D. Wagman and V. A. Medvedev, CODATA Key Values for Thermodynamics, Hemisphere, New York, 1989.

47 I. Dellien, F. M. Hall and L. G. Helper, Chromium, molybdenum, tungsten: Thermodynamic properties, chemical equilibria, and standard potentials, Chem. Rev., 1976, 76, 283-310.

48 G. W. Luther (III), S. M. Theberge, D. T. Richard and A. Oldroyd, Determination of metal (bi)sulfide stability constants of $\mathrm{Mn}^{2+}, \mathrm{Fe}^{2+}, \mathrm{Co}^{2+}, \mathrm{Ni}^{2+}$, and $\mathrm{Zn}^{2+}$ by voltammetric methods, Environ. Sci. Technol., 1996, 30, 671-679.

49 H. C. Helgeson, Thermodynamics of hydrothermal systems at elevated temperatures and pressures, Am. J. Sci., 1969, 267, 729804.

50 T. J. Wolery, Some aspects of hydrothermal processes at midocean ridges - A theoretical study. I. Basalt-sea water reaction and chemical cycling between the ocean crust and the oceans. II. Calculation of chemical equilibrium between aqueous solutions and minerals, 1978, Northwestern University, Evanston, IL.

51 D. J. Vaughan and J. R. Craig, Mineral Chemistry of Metal Sulfides, 1978, Cambridge University Press, Cambridge, UK.

52 R. M. Smith and A. E. Martell, Critical Stability Constants, New York, Plenum Press, 2nd edn., 1989, vol. 4, p. 256.

53 H. Bilinski and P. Schindler, Solubility and equilibrium constants of lead in carbonate solutions, Geochim. Cosmochim. Acta, 1982, 46, 921-928.

54 W. L. Bourcier and H. L. Barnes, Ore Solution Chemistry - VII. Stabilities of chloride and bisulfide complexes of zinc to $350{ }^{\circ} \mathrm{C}$, Econ. Geol., 1987, 82, 1839-1863.

55 J. M. Zachara, J. A. Kittrick, L. S. Dake and J. B. Harsh, Solubility and surface spectroscopy of zinc precipitates on calcite, Geochim. Cosmochim. Acta, 1989, 53, 9-20.

56 G. W. Luther (III), S. M. Theberge and D. T. Rickard, Evidence for aqueous clusters as intermediates during zinc sulfide formation, Geochim. Cosmochim. Acta, 1999, 63, 3159-3169.

57 P. Schindler, M. Reinert and H. Gamsjager, Loslichkeitskostanten und free buildungsenthalpien von $\mathrm{ZnCO}_{3}$ und $\mathrm{Zn}_{5}(\mathrm{OH})_{6}\left(\mathrm{CO}_{3}\right)_{2}$ bei $25^{\circ} \mathrm{C}$, Helv. Chim. Acta, 1969, 52, 2327-2332.

58 F. G. Smith, Lattice dimensions of cadmium sulfide, Am. Mineral., 1955, 40, 696-697.

59 F. Jellinek, The structure of chromium sulfides, Acta Crystallogr., 1957, 10, 620-628.

60 G. Brunton, Refinement of the structure of $\mathrm{K}_{2} \mathrm{Cr}_{2} \mathrm{O}_{7}$, Mater. Res. Bull., 1973, 8, 271-274.

61 N. Elliot, Interatomic distances in $\mathrm{FeS}_{2}, \mathrm{CoS}_{2}$, and $\mathrm{NiS}_{2}, J$. Chem. Phys., 1960, 33, 903-905.

62 G. George, personal communication 